\title{
A 1D-Var Approach to Retrieve Clear-Sky Wet Tropospheric Correction from Current and Future Altimetry Missions
}

\author{
Laura Hermozo, Laurence Eymard, ${ }^{\mathrm{a}}$ Fatima Karbou, ${ }^{\mathrm{b}}$ Bruno PicArd, \\ AND MICKAEL PARDÉ \\ Collecte Localisation Satellite, Ramonville-Saint-Agne, France
}

(Manuscript received 4 August 2017, in final form 14 December 2018)

\begin{abstract}
Statistical methods are usually used to provide estimations of the wet tropospheric correction (WTC), necessary to correct altimetry measurements for atmospheric path delays, using brightness temperatures measured at two or three low frequencies from a passive microwave radiometer on board the altimeter mission. Despite their overall accuracy over oceanic surfaces, uncertainties still remain in specific regions of complex atmospheric stratification. Thus, there is still a need to improve the methods currently used by taking into account the frequency-dependent information content of the observations and the atmospheric and surface variations in the surroundings of the observations. In this article we focus on the assimilation of relevant passive microwave observations to retrieve the WTC over ocean using different altimeter mission contexts (current and future, providing brightness temperature measurements at higher frequencies in addition to classical low frequencies). Data assimilation is performed using a one-dimensional variational data assimilation (1D-Var) method. The behavior of the 1D-Var is evaluated by verifying its physical consistency when using pseudo- and real observations. Several observing-system simulation experiments are run and their results are analyzed to evaluate global and regional WTC retrievals. Comparisons of 1D-Var-based TWC retrieval and reference products from classical WTC retrieval algorithms or radio-occultation data are also performed to assess the $1 \mathrm{D}-$ Var performances.
\end{abstract}

\section{Introduction}

Altimeter satellite mission data are widely used to monitor sea level and are necessary for understanding the impact of climate change on mean sea level. Since altimeters measure the altitude of the satellite above Earth's surface, retrieving sea level from these measurements requires data processing including instrument/platform corrections, accurate orbit determination, as well as accounting for atmospheric delay and surface effects. With such considerations, global and regional mean sea level (MSL) error budget from 1993 to 2012 range under 0.5 and $3 \mathrm{~mm} \mathrm{yr}^{-1}$, respectively Ablain et al. (2012).

The atmospheric propagation delay is mainly caused by water vapor in the lower-tropospheric layers and dry

\footnotetext{
${ }^{a}$ Current affiliation: Laboratoire d'Océanographie et du Climat, OSU ECCE-TERRA, Paris, France.

${ }^{\mathrm{b}}$ Current affiliation: Centre d'Etudes de la Neige, CNRMGAME, Saint-Martin d'Hères, France.
}

Corresponding author: Laura Hermozo, lhermozo@cls.fr gases in the atmosphere. The propagation delays are named the wet tropospheric correction (WTC) and dry tropospheric correction (DTC). While WTC contributes to only $10 \%$ to the total atmospheric propagation delay, it contributes to $50 \%$ of the global mean sea level error budget (Ablain et al. 2009; Obligis et al. 2010). It is thus one of the main corrections of the altimetric signal. WTC is proportional to the total column water vapor; it ranges between 0 and $50 \mathrm{~cm}$ and is highly variable in time and space. Areas of strong evaporation are associated with rather large and variable WTC (Brown 2010; Ablain et al. 2012) and its uncertainty reaches $0.74 \pm$ $0.15 \mathrm{~cm}$ (Brown et al. 2004).

WTC is generally derived from brightness temperature (TB) measurements from a nadir-viewing radiometer on board an altimeter mission at two or three dedicated frequencies, one of them being located around the $22.235 \mathrm{GHz}$ water vapor absorption line. WTC retrieval algorithms are mostly based on a regression approach making use of a database built with atmosphere state analysis from numerical weather prediction (NWP) model, or with radiosondes and other ground measurements. In these 
approaches, radiative transfer model simulations provide TB estimates, to be related with the integrated WTC. Following this approach, a multilinear regression algorithm was used by Keihm et al. (1995) to retrieve WTC, with 1.2-cm overall accuracy, using TOPEX/Poseidon Microwave Radiometer (TMR) measurements for several wind speed and cloud liquid conditions. A similar algorithm was applied by Eymard et al. (1996) to use the European Space Agency (ESA) European RemoteSensing Satellite-1 and -2 (ERS-1 and ERS-2, respectively) missions, radiometer measurements for WTC estimates. Brown et al. (2004) also used a statistical approach to retrieve WTC from the Jason Microwave Radiometer (JMR). Obligis et al. (2006) used a neural network algorithm for the inversion of the Envisat microwave radiometer measurements to estimate WTC. Picard et al. (2015) used the same approach in the context of the Satellite with Argos and Altika (SARAL) mission.

These algorithms provide WTC estimates with good accuracy over open seas. However, systematic errors may occur at regional scales, where atmospheric characteristics are not well represented in the learning database. These errors are propagated into the final sea level maps derived from altimeter data, leading to local biases. To address this issue, Obligis et al. (2009) used additional geophysical variables as inputs to the neural network algorithm (sea surface temperature and temperature lapse rate between surface and $800 \mathrm{hPa}$ ), leading to better regional performances of the retrieved WTC. As for coastal measurements, both the ocean and land surfaces contribute to the signal due to the broad measurement footprint. Such land contamination in measurements is also a source of degradation of WTC retrievals, and is caused by the large difference between land and sea TB measurements (land surface emissivity is almost 2-3 times greater than sea surface emissivity). Several methods were tested to address this specific issue. Most of them are based upon the use of TB corrections to account for the land signal within the measurement footprint (Ruf and Giampaolo 1998; Bennartz 1999; Desportes et al. 2007; Brown 2010). Other methods to update and improve the WTC in the coastal areas were also developed combining TB measurements, atmospheric model variables, and WTC derived from Global Navigation Satellite System (GNSS) data (Obligis et al. 2011). Although these methods show promising results and have a high potential to reduce estimated WTC errors over coastal areas or under various atmospheric conditions, they remain region/instrument dependent because they are dedicated to measurements from a given radiometer or because they are valid over specific regions. As an alternative, physically based methods could provide a global WTC retrieval method valid over various surfaces including oceanic and coastal areas, using observations from different sensors.

Previous studies have already shown the potential of variational methods such as one-dimensional variational data assimilation (1D-Var) approaches to retrieve temperature, humidity, and cloud vertical profiles. Over ocean, SSMIS measurements were assimilated under clear and cloudy nonprecipitating conditions by Deblonde and English (2003) to retrieve temperature and humidity profiles as well as liquid water content. Liu and Weng (2005) have shown the potential of assimilating different sets of observations from AMSU-A and AMSU-B instruments to retrieve and better constrain temperature, humidity, cloud, rain, and ice water profiles. Hewison (2007) assimilated ground-based microwave observations as well as other IR and surface sensor measurements in a 1D-Var scheme to retrieve temperature, humidity, and cloud profiles using a specific cloud classification scheme.

The 1D-Var approach was also found beneficial to estimate integrated and surface parameters, derived from retrieved atmospheric profiles and surface parameters. To address the issue of uncertainties in the estimated WTC over coastal areas, Desportes et al. (2010) showed the feasibility of using a 1D-Var approach to retrieve WTC over coastal areas by assimilating pseudomeasurements, simulated from a radiative transfer model to fit Envisat radiometer characteristics. Boukabara et al. (2011) has also developed a "multisurface" 1D-Var-based retrieval method. In the latter study, the authors perform the inversion of passive microwave observations from various instruments over ocean, land, and sea ice surfaces and for all-sky conditions to estimate derived surface or integrated products from retrievals such as sea ice concentration, rainfall rate, and cloud liquid water content among others. Note also the study conducted by Bennartz et al. (2017) to retrieve total column water vapor and WTC over ocean using measurements from the Microwave Radiometers (MWRs) onboard the ERS-1 and ERS-2 and the Envisat missions.

The latter studies demonstrate the potential of the 1D-Var approach as a relevant global method to retrieve WTC over several surfaces. Nevertheless, improvements are still required to fully exploit the benefits of the 1D-Var capabilities. For instance, the antenna pattern of each observation is not taken into account in the background information, while it provides information on the atmospheric variability around each measurement. Even though the impact is relatively low on retrieved WTC over ocean, it can be significant over coastal areas, where atmospheric and surface variabilities are rather large. High-frequency measurements (greater than $89 \mathrm{GHz}$ ) are associated with a relatively high horizontal resolution and 
with a sensitivity to atmospheric conditions and could be very useful to constrain WTC if assimilated in a 1D-Var approach. These issues should be addressed in the context of future altimeter missions, aiming to deliver a map of the topography at a higher temporal rate and smaller spatial scales, with reduced errors over various oceanic and heterogeneous surfaces.

In this study, the $1 \mathrm{D}$-Var approach is used to retrieve WTC over global ocean, with a view to extend its use over coastal areas in the near future. Different experiments are performed over ocean to validate the 1D-Var method and to assess its performance in terms of retrieved humidity and estimated WTC. A main improvement of this study as compared to the previous ones is that the frequencydependent measurement resolution is taken into account while being assimilated in the $1 \mathrm{D}-\mathrm{Var}$ scheme. Thus, the contribution of each collocated model grid cell within the measurement footprint is accounted for in the atmospheric and surface background information.

This paper is organized as follows. Data and models are described in section 2. A first evaluation of the 1D-Var using simulated observations is presented in section 3 . In section 4 we evaluate the performances of the 1D-Var using real data. Comparisons between retrieved and reference WTC estimations are performed. Conclusions are given in section 5 .

Note that a preliminary version of this article was copied in the Ph.D. manuscript describing the use of a 1D-Var approach for wet tropospheric correction estimation in the frame of altimetry missions, written by the same author.

\section{Data and methods}

\section{a. Microwave radiometer datasets}

In this study, we use measurements from the Advanced Microwave Radiometer (AMR) onboard the NASA/CNES Jason-2 Ocean Surface Topography Mission (OSTM). Dedicated to WTC estimations over ocean, the AMR provides measurements at three frequencies: 18.7, 23.8, and $34 \mathrm{GHz}$. Measurements at the $18.7-\mathrm{GHz}$ channel are mainly sensitive to ocean surface variations due to wind. Located near the $22.235-\mathrm{GHz}$ water vapor absorption band, the $23.8-\mathrm{GHz}$ channel is sensitive to water vapor in the lower part of the atmosphere whereas the 34-GHz channel is the most sensitive to clouds. AMR measurements are performed with a horizontal resolution ranging from 40 - to $20-\mathrm{km}$ main beam 3 - $\mathrm{dB}$ width, from the lowest to the highest frequency, respectively.

Frequencies and horizontal resolutions from the AMR radiometer are given in Table 1 . In addition to microwave observations, we use atmosphere and surface
TABLE 1. AMSU-A, MHS, and AMR channels and horizontal resolutions

\begin{tabular}{ccc}
\hline \hline Channel & Frequency $(\mathrm{GHz})$ & $\begin{array}{c}\text { Resolution at nadir } \\
\text { (3-dB beamwidth) }(\mathrm{km})\end{array}$ \\
\hline AMR & & \\
1 & 18.7 & 40 \\
2 & 23.8 & 20 \\
3 & 34 & 20 \\
AMSU-A & & \\
1 & 23.8 & 48 \\
2 & 31.4 & 48 \\
3 & 50.3 & 48 \\
4 & 53.6 & 48 \\
MHS & & \\
1 & 89 & 17 \\
2 & 157 & 17 \\
5 & 190 & 17 \\
\hline
\end{tabular}

fields from analyses/forecasts from the European Centre for Medium-Range Weather Forecasts (ECMWF) NWP model (ECMWF 2012). We use fields of air temperature, and specific humidity profiles at 137 pressure levels with a grid resolution of $0.25^{\circ} \times 0.25^{\circ}$, as well as fields of 2-m temperature, 2-m dewpoint temperature, surface pressure, surface skin temperature, and 2-m zonal and meridional wind speeds. These fields were taken daily, at the four synoptic hours of 0000,0600 , 1200, and 1800 UTC, for the month June 2015.

\section{b. The 1D-Var approach}

In this study we use the stand-alone 1D-Var scheme provided by the EUMETSAT Numerical Weather Prediction Satellite Application Facility (NWPSAF), available online [www.metoffice.gov.uk/research/interproj/nwpsaf (version 1.0)]. The 1D-Var system is based on linear optimal estimation to provide the best estimation of the atmosphere state vector $\mathbf{x}$, which optimally combines observation vector $\mathbf{y}$ and a background state $\mathbf{x}_{b}$ coming from short-range forecasts. An observation operator $\mathbf{H}$ is used to link the observation vector to the atmospheric state. This operator includes several interpolations from observation space to model space and radiative transfer simulations. We use the Radiative Transfer for the Television and Infrared Observation Satellite (TIROS) Operational Vertical Sounder (RTTOV), version 11.2 (Eyre 1991; Saunders et al. 1999; Matricardi et al. 2004).

The best estimation of the atmosphere state is obtained by minimizing the cost function:

$$
\begin{aligned}
\mathbf{J}(x)= & \frac{1}{2}\left[\left(\mathbf{x}-\mathbf{x}_{b}\right)^{\mathrm{T}} \mathbf{B}^{-1}\left(\mathbf{x}-\mathbf{x}_{b}\right)\right] \\
& +\frac{1}{2}\left\{\left[\mathbf{H}(\mathbf{x})-\mathbf{y}_{o}\right]^{\mathrm{T}} \mathbf{R}^{-1}\left[\mathbf{H}(\mathbf{x})-\mathbf{y}_{o}\right]\right\} .
\end{aligned}
$$


where $\mathbf{R}$ and $\mathbf{B}$ are the observation and background error covariance matrix, respectively. Superscript -1 indicates the matrix inverse and $\mathrm{T}$ its transpose.

The cost function from Eq. (1) is solved iteratively using the Levenberg-Marquardt technique. More information on the mathematical method and the convergence criteria used in the 1D-Var minimization scheme can be found in Press et al. (1988). Similar to Deblonde and English (2003), the state variables of the 1D-Var are air temperature, specific humidity, surface pressure, surface humidity, 2-m temperature, skin temperature, and zonal and meridional $10-\mathrm{m}$ wind speeds. An exception is made for cloud liquid water, which is not included in the 1D-Var state variables, here, as only clear-sky measurements are assimilated. The latter state variables all contribute to the estimation of WTC.

WTC is then estimated from the retrieved temperature and humidity profiles using the following equation:

$$
\mathrm{WTC}=\frac{k}{g} \int_{\text {surface }}^{\mathrm{TOA}} \frac{q(p)}{t(p)} d p,
$$

where $k$ is a constant, $g$ is the gravitational constant, $p$ is the pressure, and $q(p)$ and $t(p)$ are the specific humidity and temperature at a given pressure level $p$, respectively. For an optimal assimilation, observation and background error covariance matrices should be appropriately defined. The background error covariance matrix is adapted from that of the NWPSAF 1D-Var package and is modified in order to constraint humidity in the upper levels of the atmosphere and relax constraints in the lower levels. More information on this modification can be found in the appendix.

Observation errors are defined assuming no correlations between measurements at different frequencies. Observation errors for each considered channel have been estimated using 1 month of data by examining statistics of the difference between observations and simulations (noted TBdiff) following the method used in Deblonde (2001). Values of the diagonal coefficients of the observation error covariance matrix are then inferred from standard deviations of TBdiff weighted by a factor $\alpha$, between 0 and 1 . Several values of $\alpha$ have been tested and the chosen observation errors are listed in Table 2 for each assimilated observation in the 1D-Var.

\section{Evaluation of the 1D-Var retrievals using simulated data}

Pseudo-brightness temperature observations (pseudoTB) are calculated using the radiative transfer model RTTOV fed by analyses from ECMWF (profiles of clear-sky temperature and specific humidity, and surface
TABLE 2. Observation minus guess TBs and observation error standard deviations (STD) for the different 1D-Var experiments (AMR measurements assimilation and assimilation of virtualradiometer measurements). AMR and virtual-radiometer observation errors are used for the assimilation of "low frequency" and "high frequency" measurements, respectively

\begin{tabular}{|c|c|}
\hline Channel frequency $(\mathrm{GHz})$ & Observation error (K) \\
\hline \multicolumn{2}{|l|}{ AMR } \\
\hline 18.7 & 6.4 \\
\hline 23.8 & 11 \\
\hline 34 & 8.2 \\
\hline \multicolumn{2}{|l|}{ Virtual radiometer } \\
\hline 23.8 & 6.4 \\
\hline 31.4 & 7.3 \\
\hline 53.6 & 1.2 \\
\hline 89 & 6.5 \\
\hline 157 & 6.1 \\
\hline 190 & 4.3 \\
\hline
\end{tabular}

parameters over open seas). Ocean surface emissivity is estimated by the Fast Emissivity Model (FASTEM), version 5.0 (Deblonde and English 2000; Bormann et al. 2012), using model surface skin temperature and wind. To simulate current operational instruments, simulations are computed over the AMR passes, during 1 month in June 2015. Two sets of instruments are simulated: a first one called the "low frequency" configuration (noted LF) consists of simulating measurements at the AMR frequencies 18.7, 23.8, and $34 \mathrm{GHz}$; and the second one called the "high frequency" configuration (noted HF) for which measurements are simulated at 53.6, 89, 157, and $190 \mathrm{GHz}$ (AMSU-A and MHS-like instruments). As stated earlier, $53.6 \mathrm{GHz}$ is a temperature sounding channel; the other channels are sensitive to the surface and to the air moisture near the surface. The 53.6- and $190-\mathrm{GHz}$ channels can also be used for cloud screening. A Gaussian white noise of $0.5-\mathrm{K}$ standard deviation is added to pseudoTBs to simulate actual instrumental noise.

These "pseudo-observations" are then assimilated in the $1 \mathrm{D}$-Var scheme, which is fed by $24-\mathrm{h}$ forecasts from ECMWF (atmospheric profiles and surface parameters). The main advantage of this is that we know the target solution (the reference state of the atmosphere and surface), which allows a global evaluation of the 1D-Var performances. In addition, such experiments allow the evaluation of the 1D-Var using two different instrumental configurations: a classical one and a new one making use of high-frequency channel assimilation in addition to classical low frequencies. One could then evaluate the potential added value of assimilating highfrequency channels with regard to their sensitivity to the surface, tropospheric temperature, and humidity and also with regard to their improved horizontal resolution. These tests are very useful in the context of future 


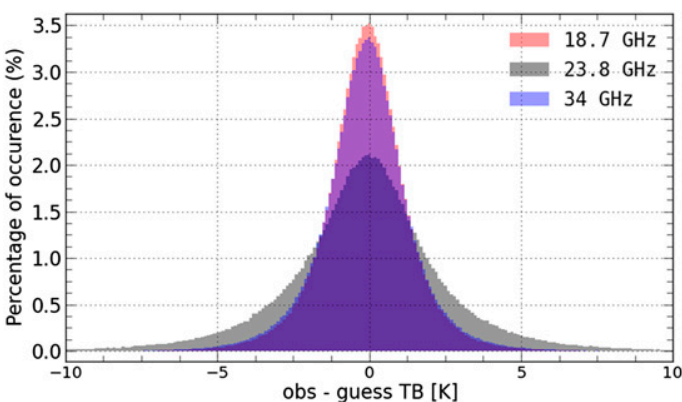

(a)

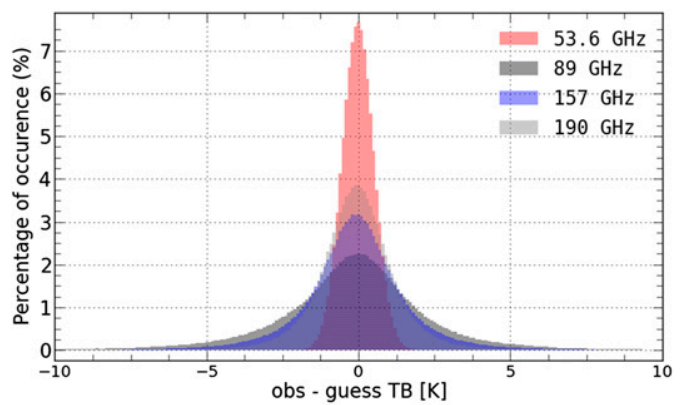

(b)

FIG. 1. Observed minus first-guess TB distributions computed over open ocean for all 1D-Var runs in June 2015 at frequencies from (a) the LF configuration $(18.7,23.8$, and $34 \mathrm{GHz})$ and (b) the $\mathrm{LF}+\mathrm{HF}$ configuration $(53.6,89,157$, and $190 \mathrm{GHz})$.

altimeter missions, such as the Jason Continuity of Service (CS) mission expected in 2020.

\section{a. Assimilation of low-frequency pseudo-TBs}

LF pseudomeasurements are first assimilated in the 1DVar scheme. Figure 1a shows the distribution of the "observed" minus first-guess TB difference $\left(\mathrm{TB}_{\text {obs }}-\mathrm{TB}_{\text {guess }}\right)$ at each frequency from the LF configuration for all 1D-Var runs during June 2015. As expected, TB differences at each frequency show typical zero-mean Gaussian distributions. Standard deviation of $\mathrm{TB}_{\mathrm{obs}}-\mathrm{TB}_{\text {guess }}$ is higher at $23.8 \mathrm{GHz}$ than at the other low frequencies, as water vapor is more variable in time and space, increasing inconsistencies between measurements and simulations. As the "target truth" is known (analyses), we compute WTC background (derived from ECMWF 24-h forecasts) and retrieved-WTC root-mean-square errors (RMSEs) with respect to the reference (derived from ECMWF analysis), named $\mathrm{RMSE}_{\text {Back }}$ and $\mathrm{RMSE}_{\mathrm{Ret}}$, respectively. This comparison allows one to evaluate the performance of the 1D-Var scheme: regarding the initial background, any improvement obtained with the $1 \mathrm{D}$-Var retrievals is shown by an RMSE reduction between background and retrieved values. Figure 2 shows a map of WTC RMSE $E_{\text {Ret }}$ minus WTC RMSE $_{\text {Back }}$ values, normalized by the reference WTC, computed within $4^{\circ}$ longitude $\times 4^{\circ}$ latitude boxes within June 2015. Some regional statistics of the 1D-Var are also examined over four specific regions, described hereafter:

- The Pacific warm pool (PWP) area, located between the Australian and South American coasts and characterized by high surface temperatures greater than $300 \mathrm{~K}$, on average over the period of study.

- The dry area in the high-latitude bands, mainly located in the Southern Hemisphere (HL area), where maximum surface humidity reaches $0.005 \mathrm{~kg} \mathrm{~kg}^{-1}$.

- Two upwelling regions located off the Horn of Africa (HA area) and along the west Californian coast
(WC area), characterized by unstable vertical stratification of specific humidity and temperature (significant decrease in humidity and temperature inversion around $850 \mathrm{hPa}$ due to high winds blowing in a parallel direction to the coast). These areas are selected according to maximum values of the temperature lapse rate between surface and $850 \mathrm{hPa}$.

Locations of study areas are plotted in Fig. 3. Figure 4 shows profiles of specific humidity $\mathrm{RMSE}_{\text {Back }}$ (dashed lines) and $\mathrm{RMSE}_{\text {Ret }}$ (continuous line), computed over the same time period and over each of the four selected areas.

Figure 2 shows that the main improvements of the 1D-Var retrieved WTC are located in the midlatitude band, where WTC is maximum. In particular, the assimilation of LF in the $1 \mathrm{D}-\mathrm{V}$ ar scheme shows an error reduction of $3 \%-4 \%$ of the WTC reference in the PWP area. This is mainly due to the highest contribution of the 23.8-GHz pseudomeasurements in the observation vector. In this area, background WTC is overestimated with respect to reference (not shown here), which is a consequence of overestimated first-guess TBs with respect to pseudo-TBs at $23.8 \mathrm{GHz}$ in the same area (as the 23.8-GHz channel is the most sensitive to water vapor in the lower layers of the atmosphere, the effect of high humidity increases simulated TB at $23.8 \mathrm{GHz}$ ). The inversion of dry pseudo-TBs at $23.8 \mathrm{GHz}$ generates lower retrieved water vapor than background, resulting in retrieved WTC closer to reference. Note that the assimilation of pseudomeasurements at the two 18.7 - and $34-\mathrm{GHz}$ channels results in a much lower retrieved-WTC error reduction, not exceeding $0.8 \%$ of reference WTC, as their sensitivity to water vapor is lower. Regarding retrieved profiles of specific humidity in the same area, improvements are significant around the $850-950-\mathrm{hPa}$ pressure levels, where $1 \mathrm{D}-$ Var retrieved errors with respect to reference are reduced by more than $10 \%$ of 

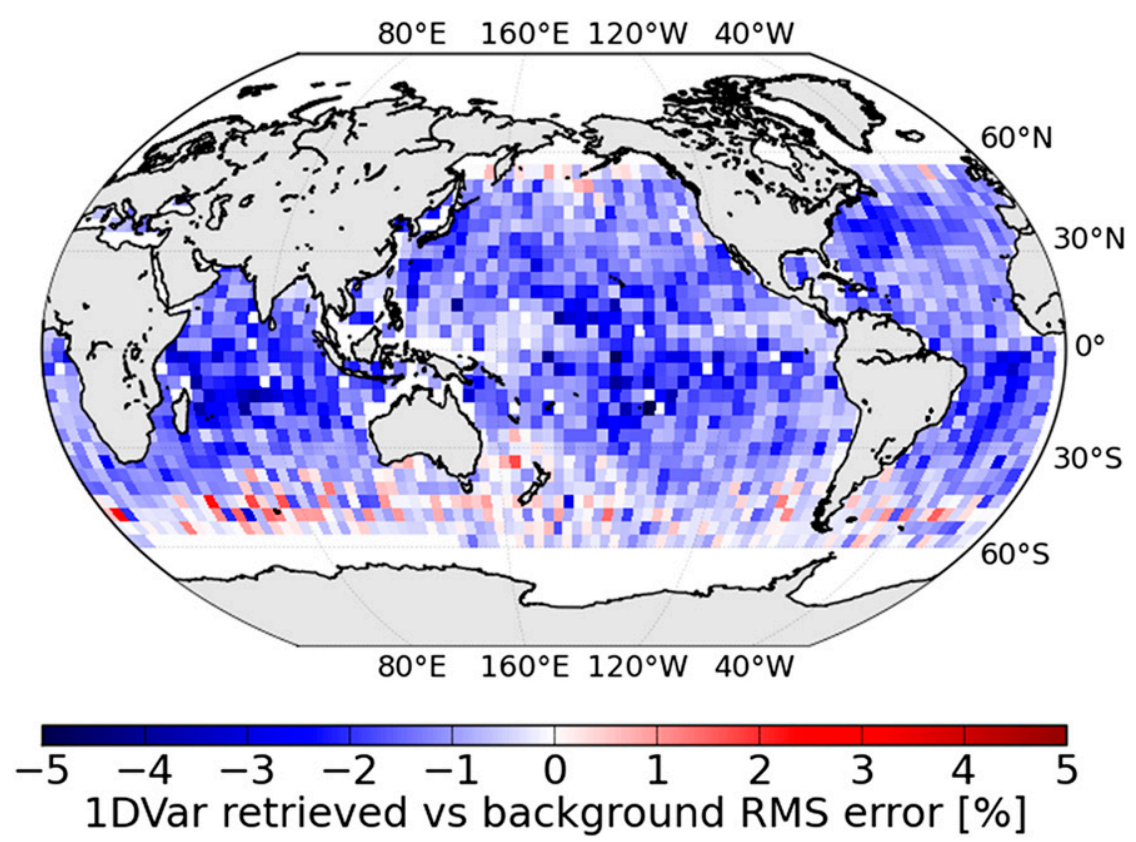

FIG. 2. Normalized RMSE differences between 1D-Var "low frequency" assimilated WTC and background WTC, with respect to the reference. RMSE is computed for $4^{\circ}$ longitude $\times 4^{\circ}$ latitude boxes for June 2015

background errors (see Fig. 4a) These levels are the main contributors to integrated WTC from surface to the top of atmosphere, reaching $8 \%$ of the total integrated WTC (not shown). Other high-surfacetemperature areas show similar results: in the Indian
Ocean and in the South Atlantic Ocean. The 1D-Var retrieved-WTC error is also reduced in comparison to background WTC error over the HA area and WC area upwelling regions. The impact of the assimilation of LF measurements is however lower than over the PWP
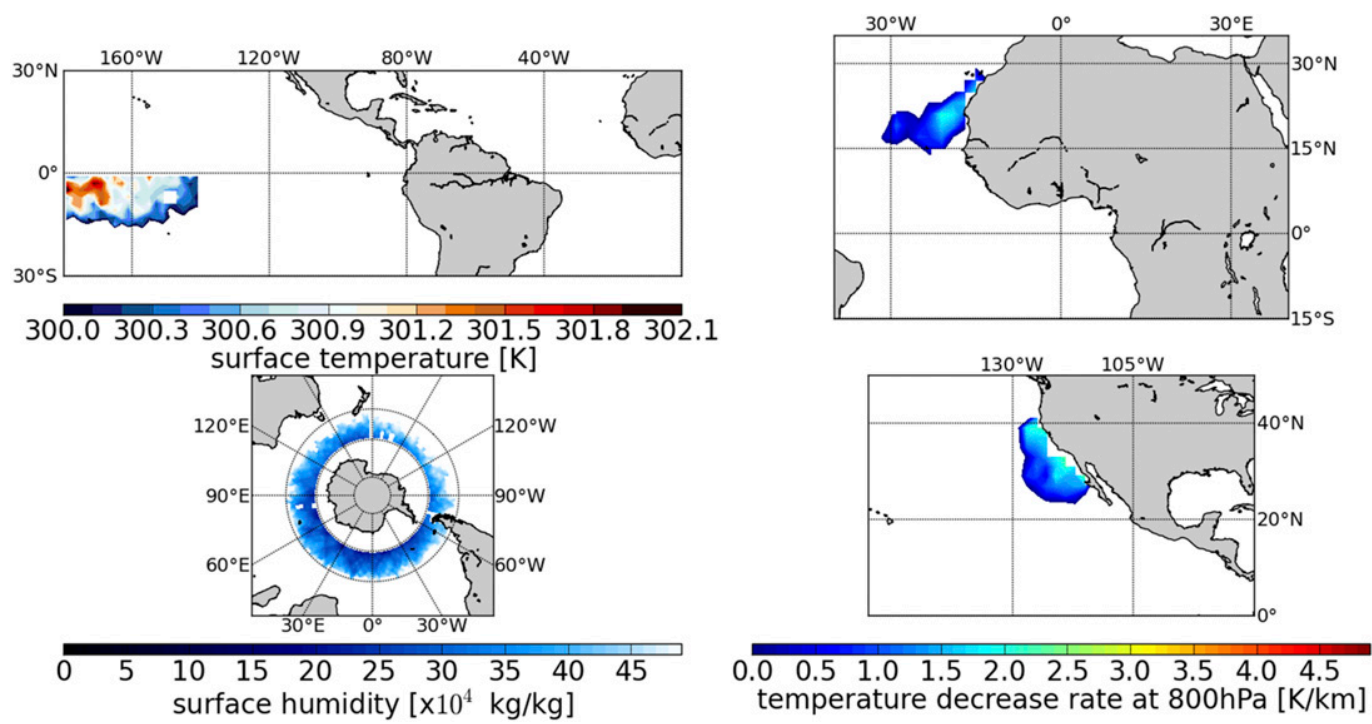

FIG. 3. Location of the four areas of study chosen according to different geophysical parameters averaged over June 2015: (top left) the PWP area driven by high surface temperatures, (bottom left) the HL area characterized by surface humidity lower than $0.005 \mathrm{~kg} \mathrm{~kg}^{-1}$, and the (top right) HA-area and (bottom right) WC-area upwelling regions characterized by a maximum temperature decrease rate values. 


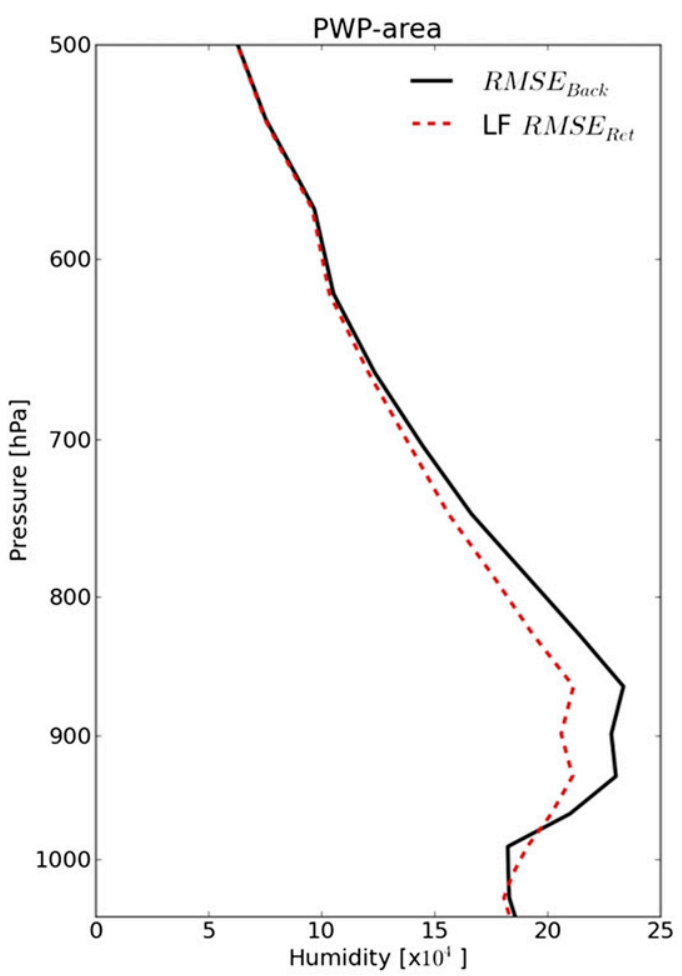

(a)

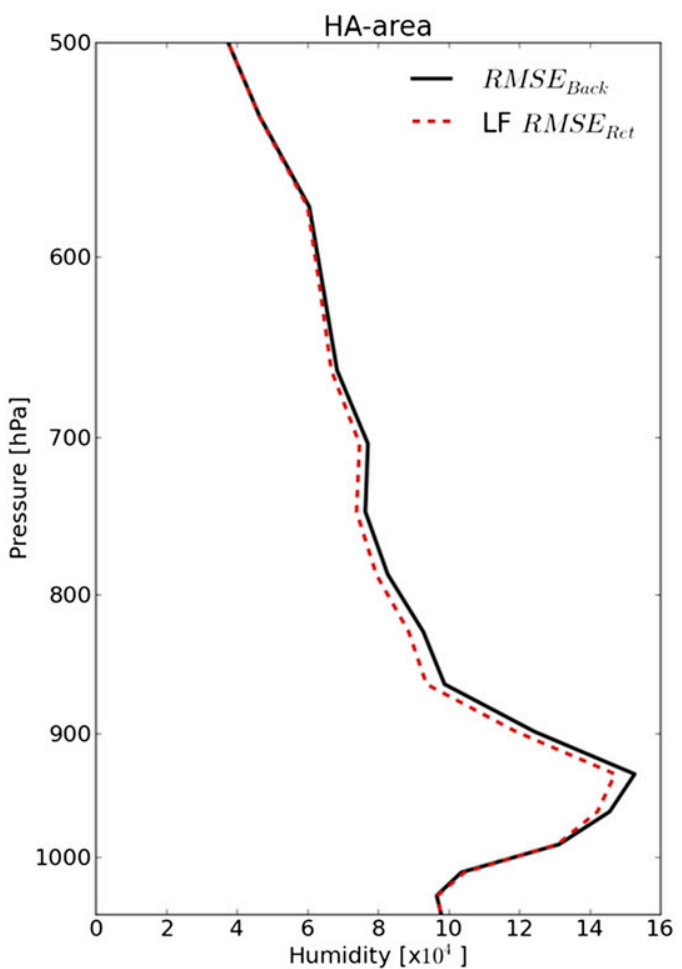

(c)

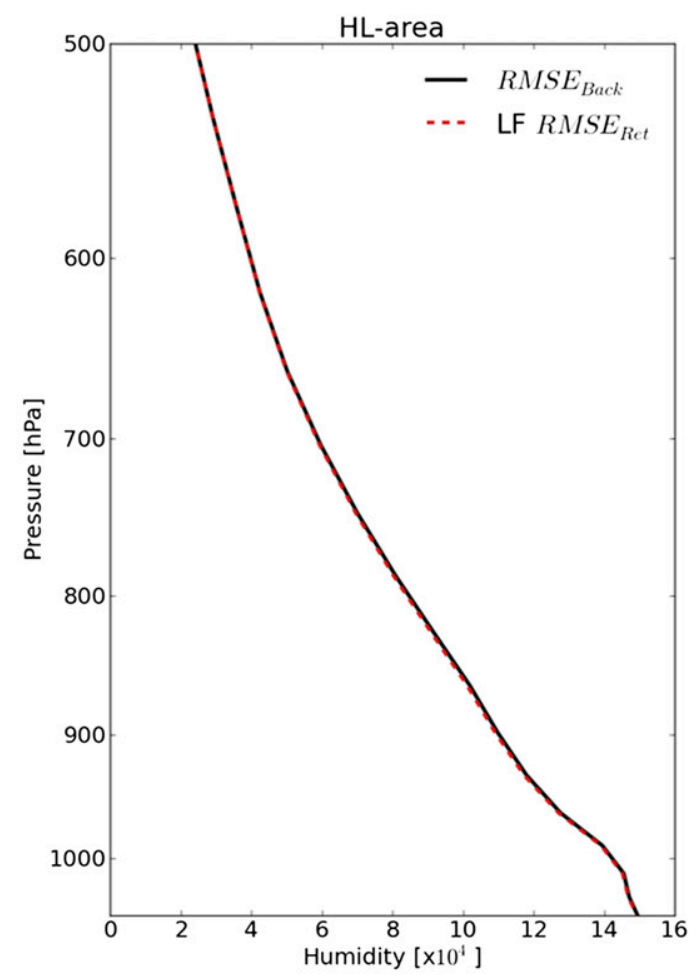

(b)

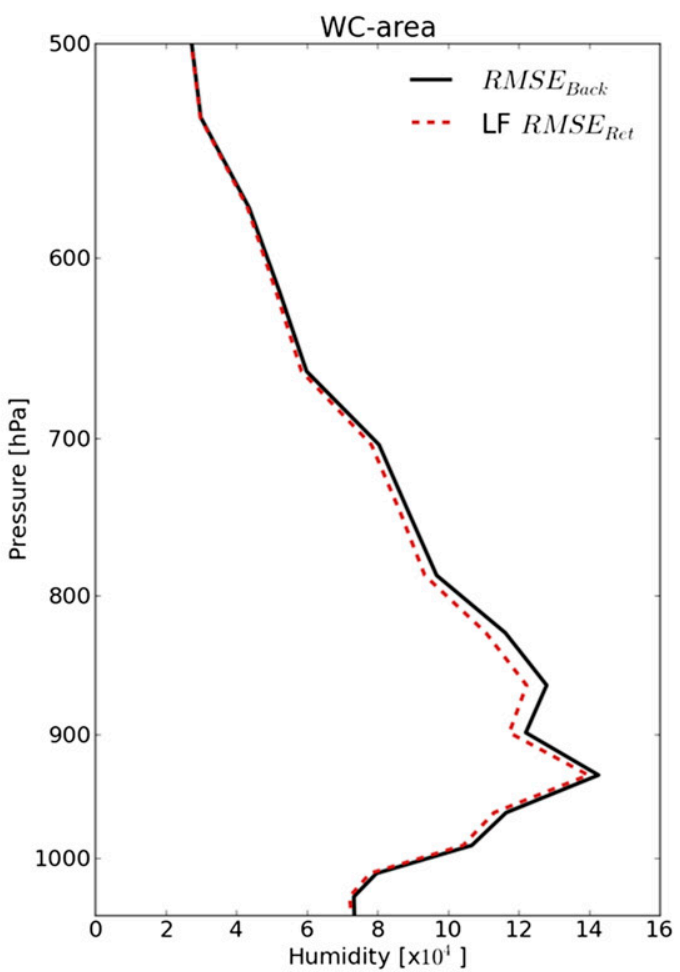

(d)

FIG. 4. The 1D-Var retrieved (dashed lines) and background (continuous lines) RMS error on specific humidity, computed over the (a) PWP and (b) HL areas and the (c) HA and (d) WC upwelling areas. Dashed lines show the results from the assimilation of LF pseudomeasurements. Statistics are computed for June 2015. 


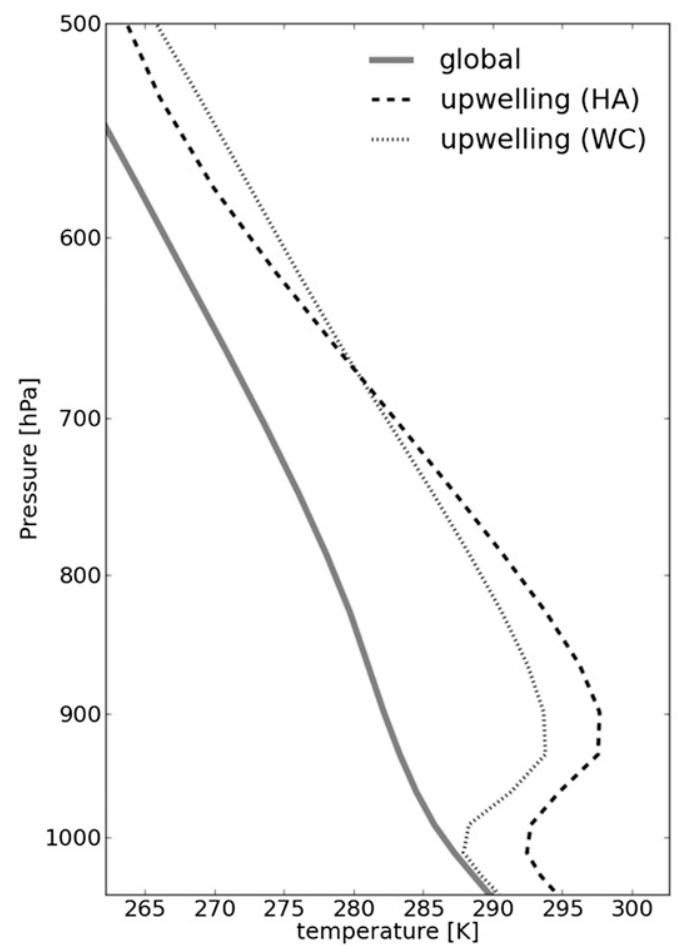

(a)

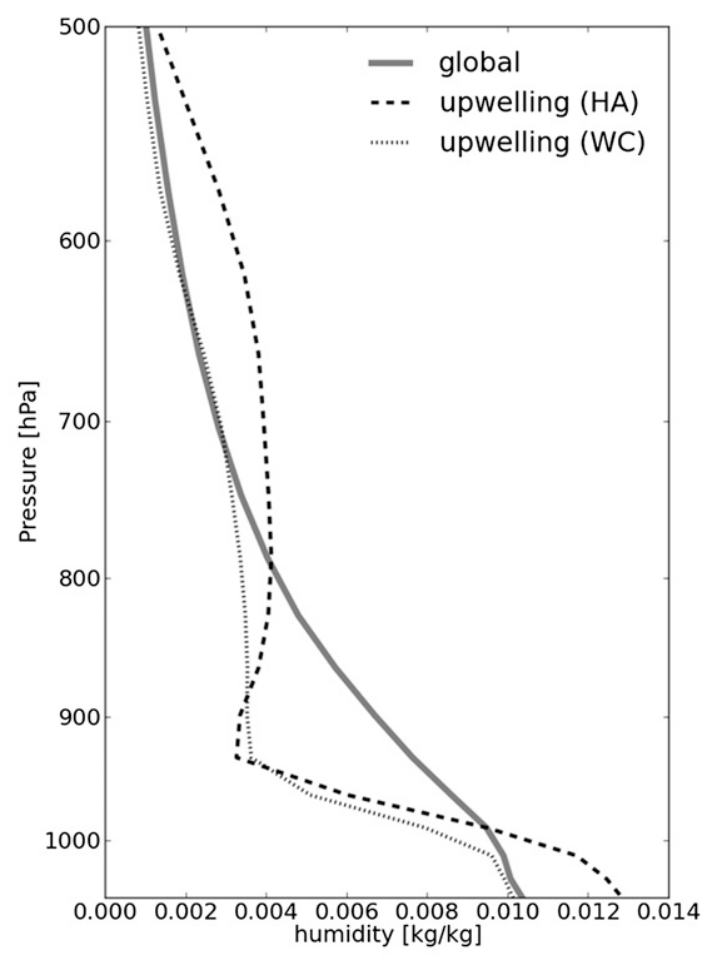

(b)

FIG. 5. Profiles of (a) temperature and (b) specific humidity averaged over WC (dotted lines) and HA (dashed lines) upwelling areas during June 2015. Profiles are compared to mean temperature and specific humidity profiles averaged over the global ocean (gray continuous line) for June 2015.

area. This is confirmed by Figs. $4 \mathrm{c}$ and $4 \mathrm{~d}$, where 1D-Var retrieved humidity RMSE reaches lower values than background RMSE in the 950-600-hPa layers only and no effect of the 1D-Var is noticed closer to the surface. Note that the $950-\mathrm{hPa}$ limit corresponds to the temperature inversion and humidity decrease point, as seen in Fig. 5. The latter illustrates the complex vertical stratification of temperature and specific humidity in both WC and HA upwelling areas. Profiles are averaged over June 2015 over both areas (dashed lines) and compared to those averaged over the global ocean (continuous line).

Over dry areas such as in the HL area, the impact of the assimilation of LF artificial measurements on retrieved humidity and estimated WTC is weak. Figure 4b shows very similar profiles of background and retrieved specific humidity errors, which results in a weak reduction of WTC RMSE $E_{\text {Ret }}$ compared to RMSE $E_{\text {Back }}$. These error statistics include some small local degradations of the 1D-Var retrievals with respect to reference, with retrieved minus background WTC RMSE difference between $0 \%$ and $+1 \%$ of reference WTC (see Fig. 2). In these localized regions, background (derived from ECMWF 24-h forecasts) minus reference (derived from ECMWF analysis) WTC difference is high, with an overestimated background WTC of more than $1 \mathrm{~cm}$ regarding reference WTC.

\section{b. Assimilation of high-frequency measurements in the 1D-Var}

To evaluate the potential of high frequencies in the 1D-Var, pseudo-TBs at 53.6, 89, 157, and $190 \mathrm{GHz}$ are assimilated in the 1D-Var in addition to the "classical" low frequencies at $18.7,23.8$, and $34 \mathrm{GHz}$. Similarly to the assimilation of the LF pseudomeasurements, the observed minus first-guess TB distribution at each assimilated high frequency is shown in Fig. 1b for all $1 \mathrm{D}-$ Var runs in June 2015. Note that $\mathrm{TB}_{\mathrm{obs}}-\mathrm{TB}_{\text {guess }}$ differences at $53.6 \mathrm{GHz}$ show the lowest standard deviation. The overall statistics for the other channels are rather satisfactory.

Performance of the 1D-Var assimilating this new set of frequencies (named LF+HF) is analyzed during June 2015 and compared to the performance of the 1D-Var retrievals obtained by assimilating LF pseudomeasurements. The $\mathrm{LF}+\mathrm{HF}$ retrieved minus background RMSE difference (not shown here) shows similar patterns to those of Fig. 2, but with higher intensity in the negative values. Thus, high frequencies contribute to reducing even more the retrieved-WTC errors regarding the 

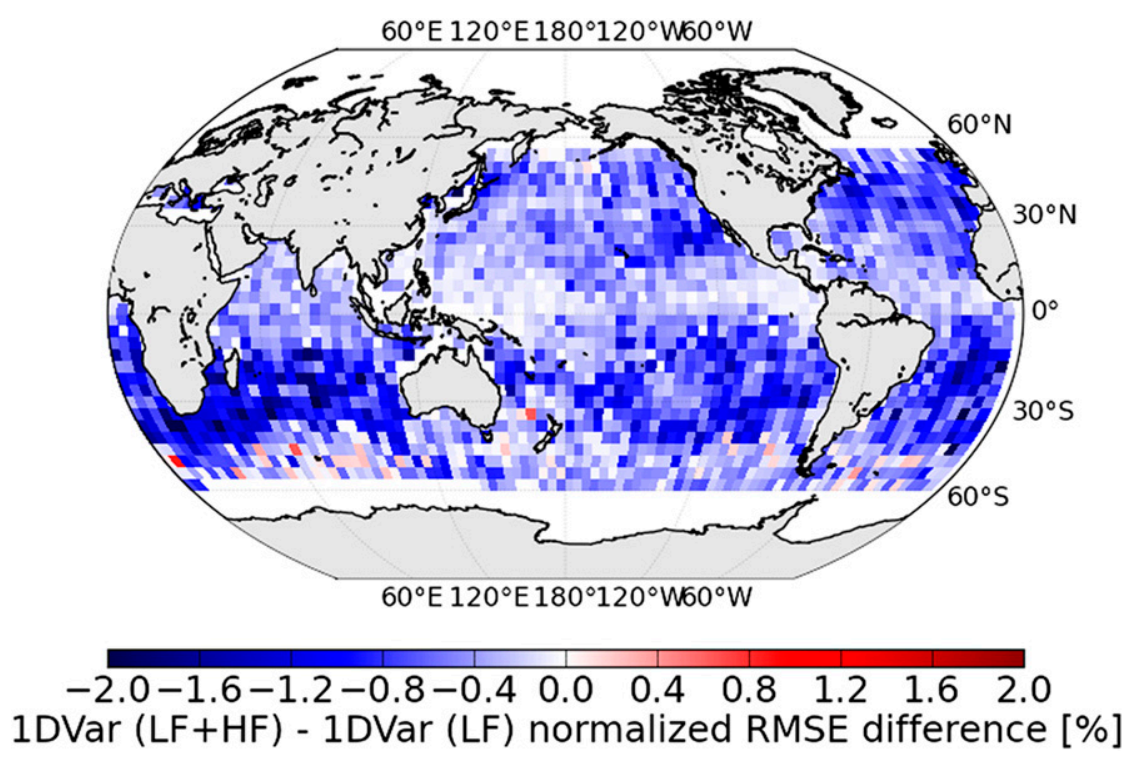

FIG. 6. The 1D-Var retrieved-WTC normalized RMSE difference between the assimilation of $\mathrm{LF}+\mathrm{HF}$ and of LF artificial measurements. Statistics are averaged in $4^{\circ}$ latitude $\times 4^{\circ}$ longitude boxes over a 1-month period in June 2015.

background, with maximum WTC RMSE reduction between background and retrievals reaching $5 \%$ of reference WTC. To quantify the improvement with respect to LF retrieved-WTC performance, Fig. 6 shows the WTC RMSE $_{\text {Ret }}$ difference between the LF+HF configuration and the LF configuration, computed over June 2015. An improvement of $\mathrm{LF}+\mathrm{HF}$ retrieved WTC regarding $\mathrm{LF}$ retrieved WTC is shown by negative values (in blue). Conversely, positive values (in red) mean a degradation of LF + HF retrieved WTC regarding LF retrieved WTC. The main impact of high frequencies in the 1D-Var scheme on retrieved WTC is located in the mediumlatitude bands. A study of the separate contribution of each high frequency on retrieved WTC shows that the contribution of both the 89 - and the $157-\mathrm{GHz}$ channels in the observation vector is predominant in these areas. This results in a larger WTC error reduction in the WC area and HA area upwelling regions as well as in the PWP area, by almost $2 \%$ of reference WTC, regarding LF WTC RMS error. Similar features are seen in the South Atlantic and southern Indian Oceans. According to integrated cloud liquid water content and zonal and meridional wind speed fields from ECMWF analysis, these regions are mainly related to clear-sky conditions and medium to low wind speeds in June 2015. In such areas, where sources of model/measurement inconsistencies are reduced, the extra surface information brought by the 89- and $157-\mathrm{GHz}$ channels contributes to retrieving drier WTC than background and than LF retrieved WTC, thus closer to reference WTC. Pseudo-TBs at $190 \mathrm{GHz}$ also contribute to reduce retrieved-WTC RMSE regarding
LF retrieved-WTC RMSE, but at a smaller scale (the error reduction does not exceed $0.5 \%$ of reference WTC). Nevertheless, as it is the most sensitive channel to cloud liquid water droplets, this channel is an accurate proxy for cloud screening. In addition to this characteristic, the assimilation of $190-\mathrm{GHz}$ measurements could provide an additional constraint to retrieve cloud liquid water, as part of further plans for the use of the 1D-Var.

Finally, the impact of the 53.6-GHz channel pseudomeasurements in the 1D-Var scheme on retrieved WTC is low: it shows neither an increased nor a decreased retrieved-WTC RMSE regarding LF retrieved-WTC RMSE. This can be explained as the 53.6- $\mathrm{GHz}$ channel is highly sensitive to temperature variations in higher pressure levels (levels that contribute less to total integrated WTC), while background (from 24-h forecasts) and reference (from analysis) temperature profiles show weak differences. In addition, profiles of temperature are highly constrained in the 1D-Var, as background temperature errors (standard deviation errors) do not exceed $1 \mathrm{~K}$ from the surface to the other levels of the atmosphere.

Figure 7 shows profiles of RMSE $\mathrm{Ret}_{\text {(dashed lines) }}$ and $\mathrm{RMSE}_{\text {Back }}$ (continuous lines) on specific humidity, computed over the four areas of study (Fig. 7a shows the PWP area, Fig. 7b shows the HL area, Fig. 7c shows the WC area, and Fig. 7d shows the HA area) during June 2015. The contribution of high-frequency pseudomeasurements in the assimilation scheme on retrieved WTC is highlighted by an error reduction in profiles of retrieved specific humidity in the PWP area and over the WC-area and HA-area upwelling regions. The main 


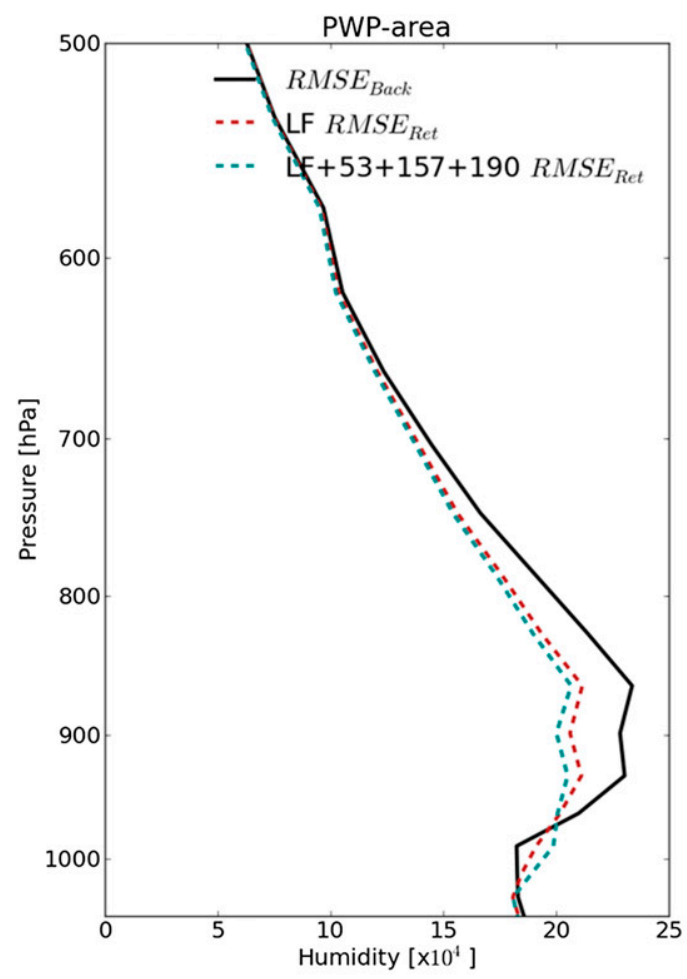

(a)

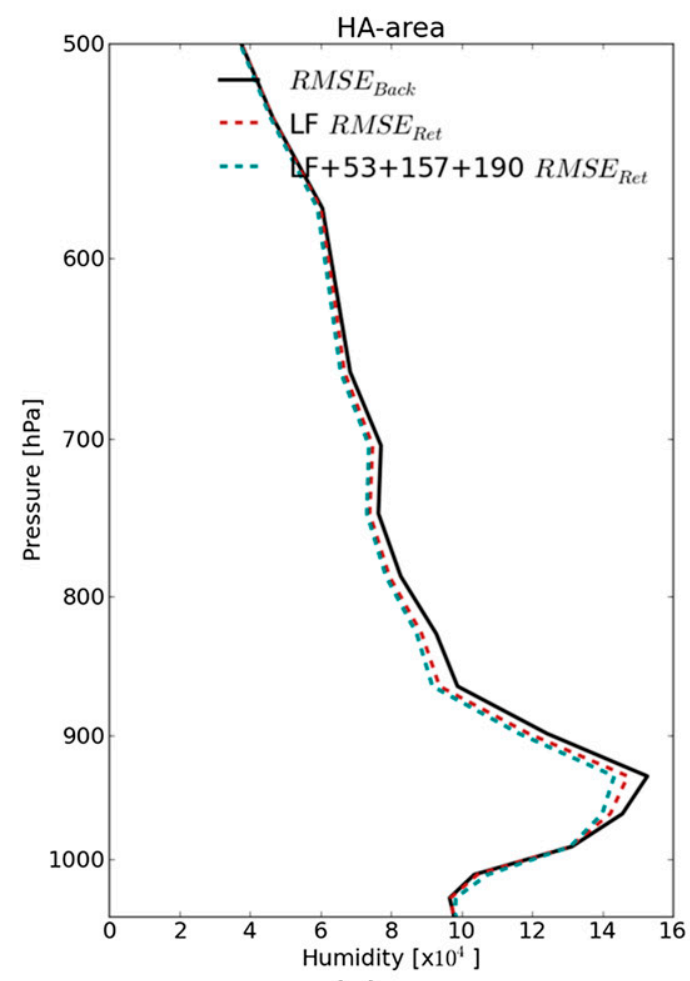

(c)

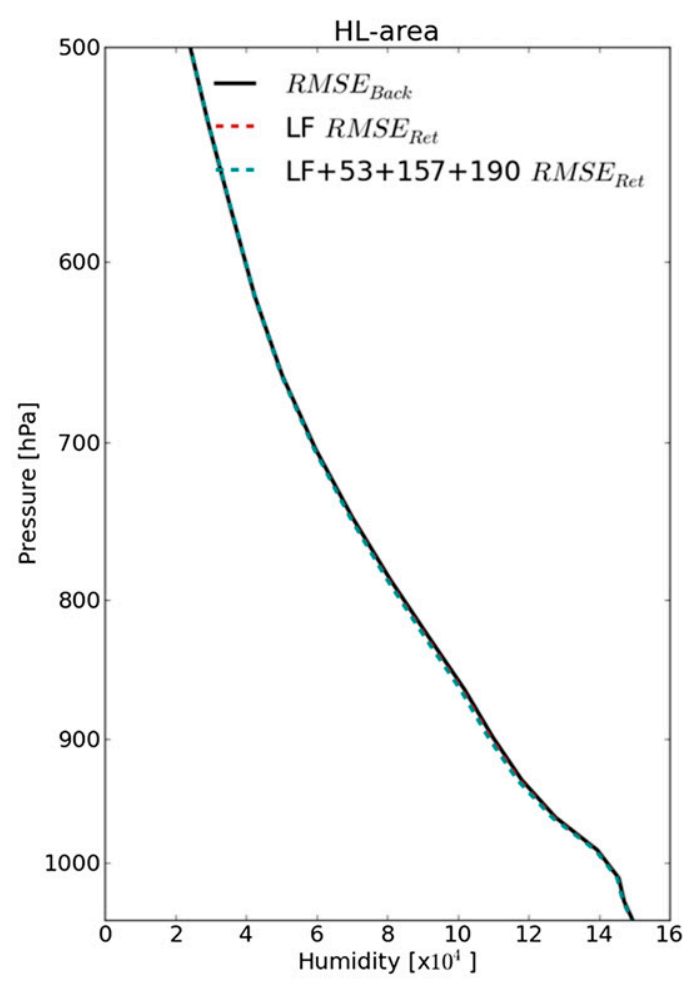

(b)

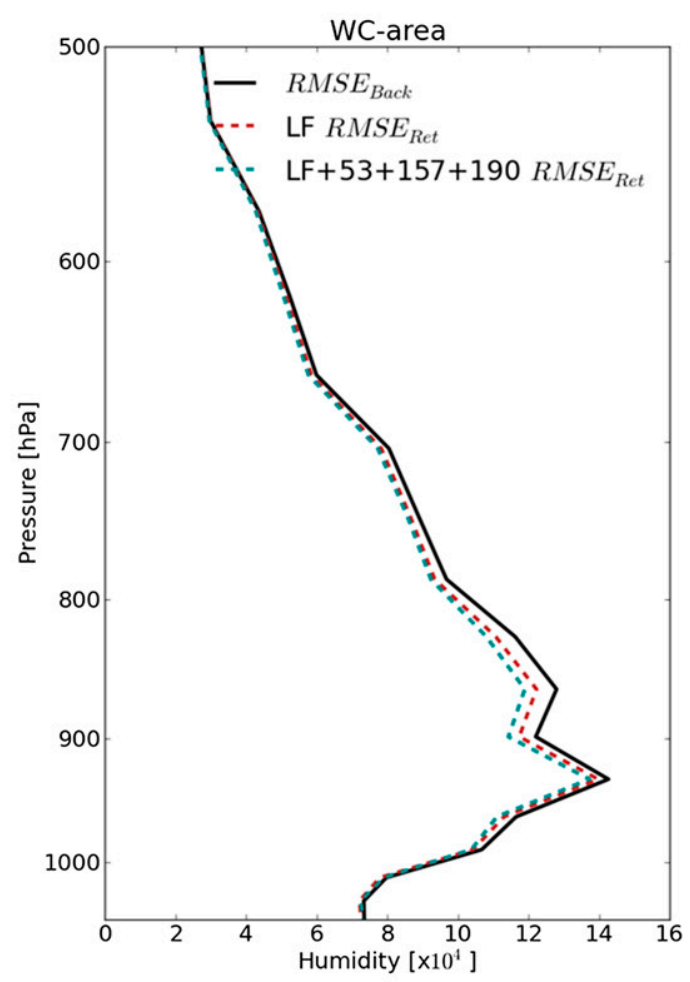

(d)

FIG. 7. The 1D-Var retrieved (dashed lines) and background (continuous lines) RMSE on specific humidity, computed over the (a) PWP and (b) HL areas and the (c) HA and (d) WC upwelling areas. Red dashed lines show the results from the assimilation of LF pseudomeasurements, and cyan dashed lines show results from the assimilation of LF $+53+157+190$ pseudomeasurements. Statistics are computed for June 2015 . 


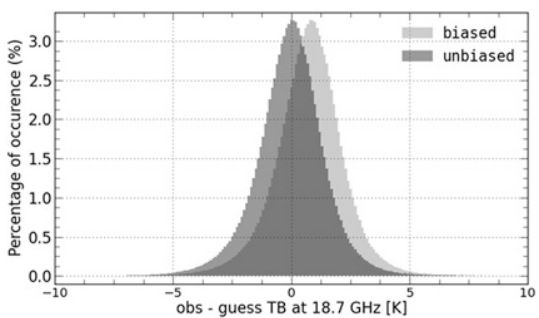

(a)

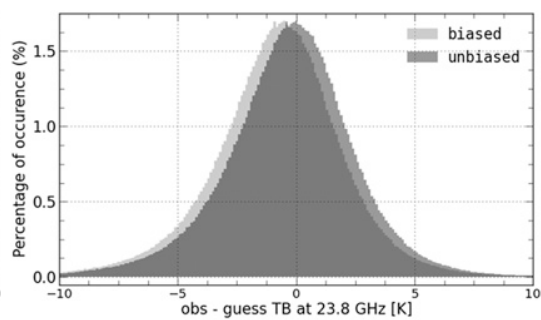

(b)

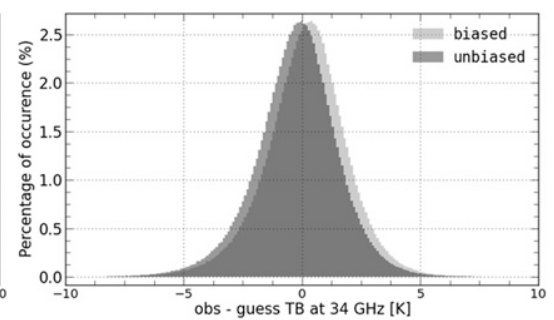

(c)

FIG. 8. AMR observed minus first-guess TB difference at (a) 18.7, (b) 23.8, and (c) $34 \mathrm{GHz}$ without bias correction (light gray) and with bias correction (dark gray), computed over the 6-month time period from June to November 2015.

improvement is shown between the $800-$ and $950-\mathrm{hPa}$ pressure levels, levels contributing the most to total integrated WTC. As expected, a very weak error reduction in profiles of specific humidity is shown in the HL area, where surface humidity does not exceed $0.005 \mathrm{~kg} \mathrm{~kg}^{-1}$, even when assimilating the HF artificial measurements in addition to the LF configuration. According to Fig. 6, high frequencies contribute to reducing the retrieved-WTC error of under $0.5 \%$ more than LF retrieved-WTC error. In such areas, this improvement is negligible regarding the weak WTC values in our reference dataset.

\section{Impact of real observations on retrieved WTC}

\section{Inversion of AMR (Jason-2) measurements}

In the previous section, we have shown the impact of the assimilation of simulated measurements using the 1D-Var scheme on retrieved WTC, with a set of experiments using low-frequency or high-frequency microwave observations. In this section, the impact of the 1D-Var on WTC when assimilating real observations is evaluated over open seas and under clear-sky conditions.

Clear-sky AMR measurements are assimilated over ocean four times daily at 0000, 0600, 1200, and 1800 UTC over a 6-month time period, from June to November 2015. To feed the 1D-Var, background fields were taken from ECMWF analyses to use the best estimate of the atmosphere/surface state. To avoid any land contamination in the assimilated measurements, oceanic measurements are selected when they are located at least $50 \mathrm{~km}$ away from the coast.

Cloudy situations are screened out using the model background and observations. Concerning the model, profiles of cloud liquid water with nonzero values are taken to screen out cloudy scenes. In addition, we also used liquid water path product, available from the Geophysical Data Record (GDR) products [see Keihm et al. (1995) for more information on the liquid water path estimation algorithm]. Only measurements for which liquid water path is zero are used. Finally, to avoid remaining inconsistencies between measured and simulated TBs, measurements are rejected if the observed minus first-guess TB difference is greater than 2 times the measured minus simulated data standard deviation computed over 1 month prior to the assimilation period. These a priori statistics also allow deriving mean values for each channel to bias correct RTTOV simulations. The obtained observed minus first-guess TB difference at each frequency shows a 0 -mean Gaussian distribution, as illustrated in Fig. 8 at 18.7 (Fig. 8a), 23.8 (Fig. 8b), and $34 \mathrm{GHz}$ (Fig. 8c).

Retrieved WTC, noted as $\mathrm{WTC}_{1 \mathrm{DVAR}}$, is compared to WTC estimated from the operational log-linear algorithm, available from the GDR products, named $\mathrm{WTC}_{\mathrm{AMR}}$.

Figure 9 shows the scatterplot of $\mathrm{WTC}_{\mathrm{AMR}}$ versus WTC $_{1 \mathrm{DVAR}}$, computed over open ocean from June to November 2015. One can note the overall good consistency on average between WTC estimated from the operational AMR WTC retrieval algorithm and 1D-Var retrieved WTC, with a mean difference around $0.5 \mathrm{~cm}$ over global ocean. As current WTC retrieval algorithms are known to have good performance over clear-sky global ocean, $\mathrm{WTC}_{\mathrm{AMR}}$ shows rather low uncertainty (Brown et al. 2004). Thus, this plot underlines the ability of the $1 \mathrm{D}-$ Var to be at least as good as current algorithms' performance in global oceanic clear-sky conditions. However, Fig. 9 shows more scattered values resulting in a $1.5-\mathrm{cm}$ standard deviation error. These scattered values represent less than $5 \%$ of the maximum bin population and correspond to $\mathrm{WTC}_{\mathrm{AMR}}$ values ranging between 0 and $30 \mathrm{~cm}$. Most of the large differences seen between $\mathrm{WTC}_{\mathrm{AMR}}$ and $\mathrm{WTC}_{1 \mathrm{DVAR}}$ are explained by the coarse cloud screening used in this study. This results either in the assimilation of cloudy measurements while assuming clear sky in the inversion process, or in the assimilated of clear-sky observations while using cloudy first-guess temperature and humidity profiles. In the first case, this causes the retrieval of underestimated water vapor with respect to observations, as cloud liquid water is not part of the control 


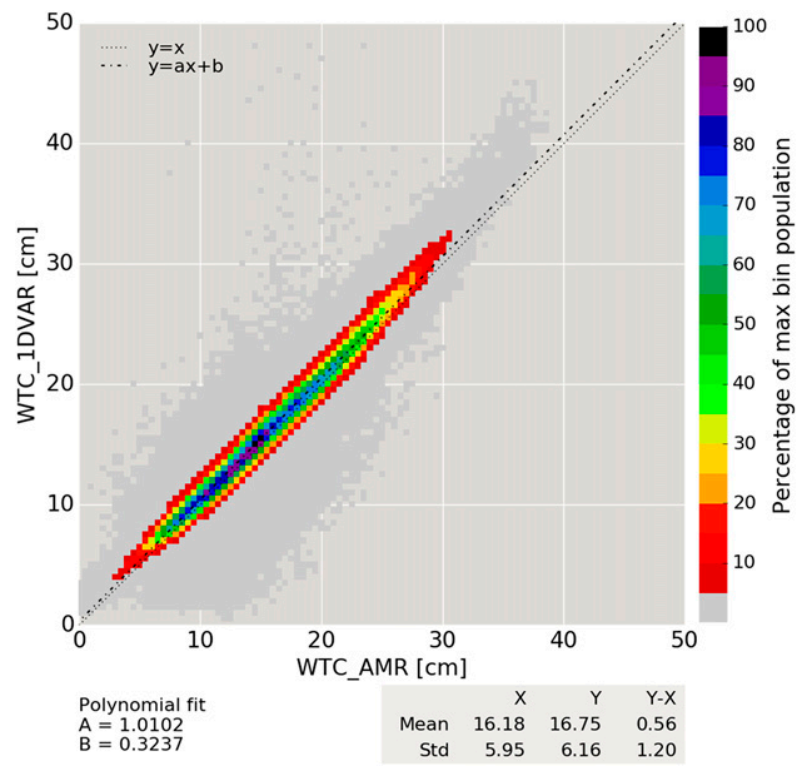

FIG. 9. Dispersion of AMR WTC estimated from current algorithms $\left(\mathrm{WTC}_{\mathrm{AMR}}\right)$ vs $1 \mathrm{D}-\mathrm{Var}$ retrieved WTC (WTC 1 DVAR $)$ obtained by assimilating clear-sky AMR measurements over ocean. Statistics are computed over a 6-month period of study from June to November 2015.

vector, so the minimization process cannot converge to water vapor close enough to observations. In the second case, this causes the retrieval of overestimated specific humidity and thus overestimated $\mathrm{WTC}_{1 \mathrm{DVAR}}$ with respect to $\mathrm{WTC}_{\mathrm{AMR}}$, by more than $10 \mathrm{~cm}$ in some cases. In addition to these observations, areas of strong stratification in the subtropical region, similar to upwelling areas, may cause higher uncertainties in $\mathrm{WTC}_{\mathrm{AMR}}$ and explain the overestimated values, which questions the use of $\mathrm{WTC}_{\mathrm{AMR}}$ as an absolute reference.

To further evaluate the impact of the inversion of AMR measurements on retrieved WTC, WTC $_{1 \text { DVAR }}$ is also compared with independent data over the period of study. The latter are derived from radio-occultation measurements provided by the Radio-Occultation Meteorology Satellite Application Facility (ROM SAF), named $\mathrm{WTC}_{\mathrm{RO}}$. Collocated $\mathrm{WTC}_{\mathrm{RO}}$ data are selected if they are located within $100 \mathrm{~km}$ and $1 \mathrm{~h}$ of the AMR assimilated measurements, to ensure both time and spatial consistency. Figures 10a and $10 \mathrm{~b}$ show the scatterplots of $\mathrm{WTC}_{\mathrm{RO}}$ versus $\mathrm{WTC}_{1 \mathrm{DVAR}}$ and versus $\mathrm{WTC}_{\mathrm{AMR}}$, respectively. Despite the small number of collocations over the period of study, Fig. 10a illustrates the good agreement between $1 \mathrm{D}$-Var retrieved and radio-occultation WTC. A higher dispersion of $\mathrm{WTC}_{1 \mathrm{DVAR}}$ values with respect to $\mathrm{WTC}_{\mathrm{RO}}$ is noticed for less than $5 \%$ of the total number of observations. One can notice the slightly more linear relationship between $\mathrm{WTC}_{1 \mathrm{DVAR}}$ and $\mathrm{WTC}_{\mathrm{RO}}$ compared to $\mathrm{WTC}_{\mathrm{AMR}}$ in Fig. $10 \mathrm{~b}$, as shown by the polynomial fit (dash-dotted line) on both plots. This is due to lower $\mathrm{WTC}_{\mathrm{AMR}}$ than $\mathrm{WTC}_{\mathrm{RO}}$, and closer $\mathrm{WTC}_{1 \mathrm{DVAR}}$ to $\mathrm{WTC}_{\mathrm{RO}}$, for values of $\mathrm{WTC}_{\mathrm{RO}}$ ranging between 25 and $35 \mathrm{~cm}$. Note that Fig. 9 shows the same trend for high values of WTC: WTC $_{\text {AMR }}$ is drier than WTC $_{1 \text { DVAR }}$ for values ranging between 25 and $35 \mathrm{~cm}$.

Mean difference of retrieved minus background WTC $\left(\right.$ WTC $_{1 \text { DVAR }}-$ WTC $\left._{\text {BACK }}\right)$ is computed as well as mean difference of retrieved minus AMR-derived WTC $\left(\mathrm{WTC}_{1 \mathrm{DVAR}}-\mathrm{WTC}_{\mathrm{AMR}}\right)$ and are both illustrated in Figs. 11a and 11b, respectively. It shows the gridded average of the differences over the same 6-month period of study in $2^{\circ}$ longitude $\times 2^{\circ}$ latitude boxes, which ensure a sufficient number of observations in each bin. As seen in Fig. 12, the number of clear-sky observations in each grid cell mainly exceeds 100 per bin. However, due to the clear-sky filtering, this number decreases when moving toward high latitudes and close to the ITCZ. This also explains the need of a relatively long period to evaluate the impact of the 1D-Var on retrieved WTC for Jason-2 altimeter mission.

One can notice the dryer $\mathrm{WTC}_{\mathrm{AMR}}$ than $\mathrm{WTC}_{1 \mathrm{DVAR}}$ around the ITCZ (where $\mathrm{WTC}_{\mathrm{AMR}}$ exceeds $30 \mathrm{~cm}$ ) and in the high-latitude bands, with differences ranging from 1 to $2 \mathrm{~cm}$, respectively (Fig. 11b). Note that the higher differences in the Southern Hemisphere, located around the $60^{\circ} \mathrm{S}$ latitude band, correspond to sea ice occurrence during the winter period (from June to September). Localized minimum differences in both the ITCZ and the high-latitude bands poleward of $60^{\circ} \mathrm{N}$ and $60^{\circ} \mathrm{S}$ should be interpreted with care as they are located in regions where valid clear-sky observations are scarce (under 50 observations in each grid cell; see Fig. 12).

Figure 11a shows clear impact of the 1D-Var on background WTC in low- and midlatitude bands, with retrieved WTC drier than background of about 0.5$1 \mathrm{~cm}$. As seen in Fig. 11b, this results in low differences between retrieved and radiometer WTC in the same areas. This is the case in the PWP area (see section 3 and Fig. 3), characterized by maximum sea surface temperature and high WTC temporal variability within a year (not shown here).

Even though fewer observations are assimilated in the ITCZ, one can notice the overestimated $\mathrm{WTC}_{1 \mathrm{DVAR}}$ with respect to $\mathrm{WTC}_{\mathrm{AMR}}$, ranging from 1 to $2 \mathrm{~cm}$. This is mainly a result of higher observed minus first-guess TB differences at $23.8 \mathrm{GHz}$ (the most sensitive channel to water vapor), followed by the $34-\mathrm{GHz}$ channel. In this region, first-guess TBs are overestimated by $3-4 \mathrm{~K}$ with respect to measurements at $23.8 \mathrm{GHz}$, resulting from a wetter background atmosphere than radiometer measurements. This gap makes the 1D-Var minimization 


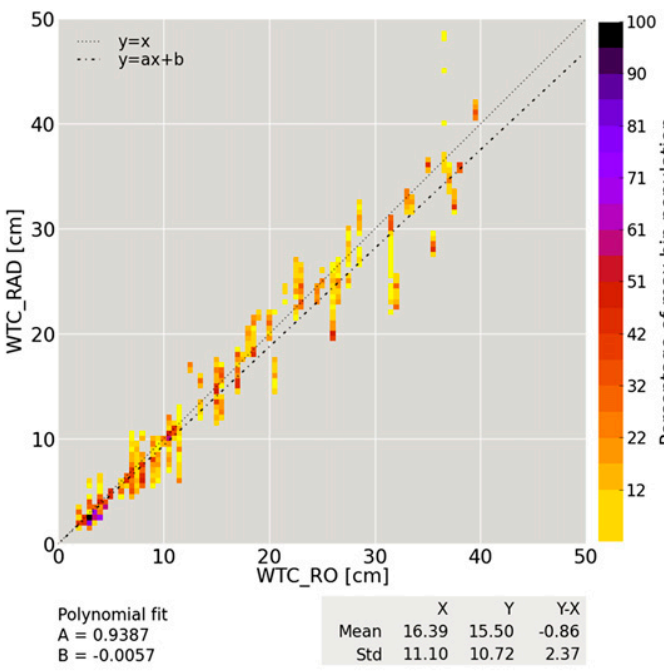

(a)

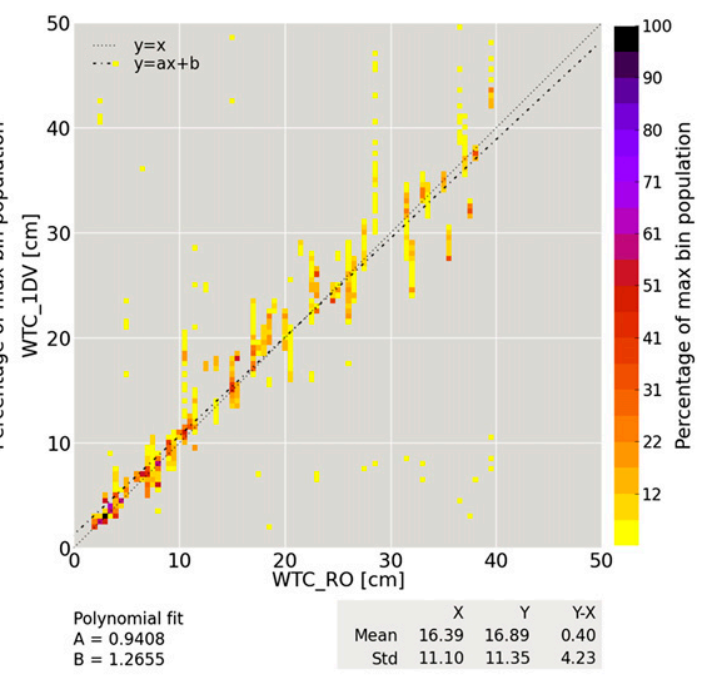

(b)

FIG. 10. Dispersion of WTC estimated from collocated radio-occultation (WTCRO) vs (a) 1D-Var retrieved WTC (WTC1DVAR) obtained by assimilating all-sky AMR measurements over ocean and (b) WTC estimated from the current operational algorithm for Jason-2 mission (WTCAMR). Statistics are computed over a 6-month period of study from June to November 2015.

process difficult and retrieved WTC remain wetter than WTC $_{\text {AMR }}$.

Figure $11 \mathrm{~b}$ shows that the high-latitude band is characterized by an overestimation of retrieved WTC with respect to $\mathrm{WTC}_{\mathrm{AMR}}$. This overestimation cannot be seen in Fig. 11a because the impact of the inversion of AMR measurements on background WTC in the highlatitude band is very weak. This confirms that overestimated $\mathrm{WTC}_{1 \mathrm{DVAR}}$ with respect to $\mathrm{WTC}_{\mathrm{AMR}}$ in the high-latitude band is mainly due to the already existing differences between radiometer and background WTC. Part of these model background/observations inconsistencies can be explained by the time gap between both datasets, which can be as large as $3 \mathrm{~h}$ from the model background (provided four times daily at 0000, 0600, 1200 , and 1800 UTC) in a highly variable atmosphere characterizing the high-latitude bands.

Even though current WTC retrieval algorithms are globally robust over ocean, they generally show higher uncertainties in areas where atmospheric conditions
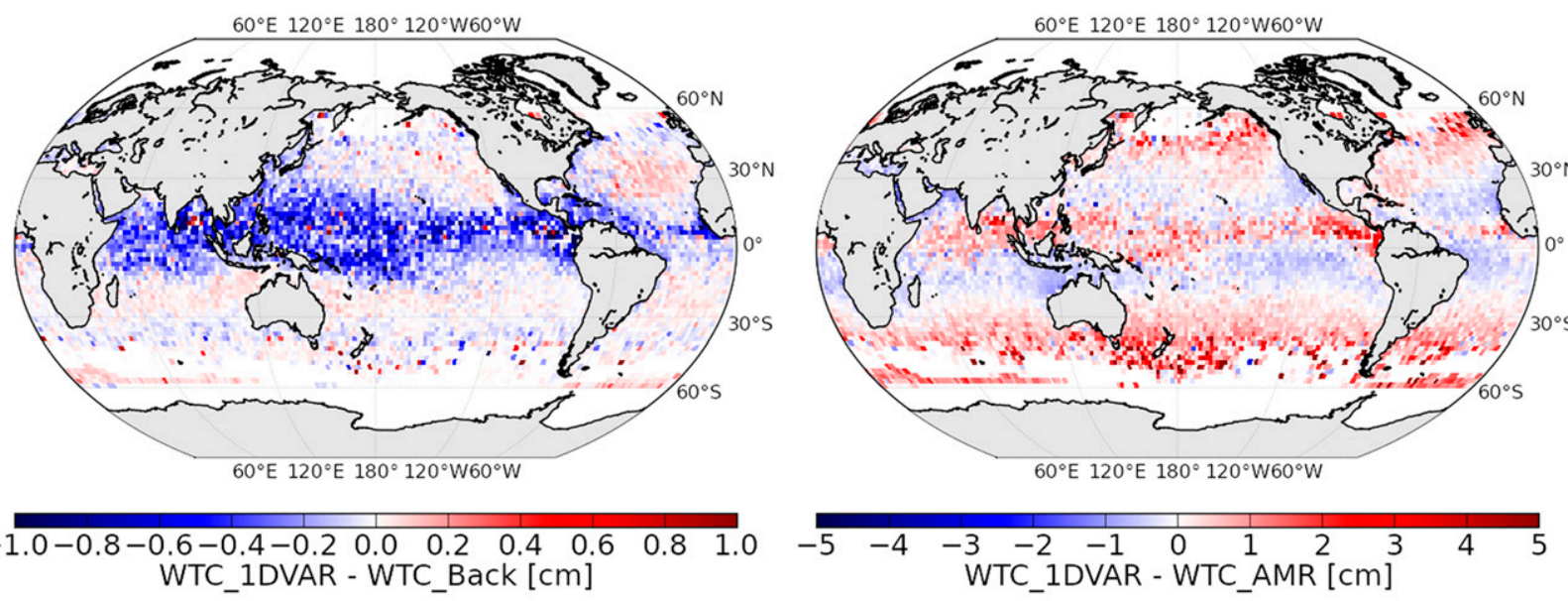

(b)

(a)

FIG. 11. The 1D-Var (a) retrieved minus background WTC and (b) retrieved minus AMR WTC estimated from the operational algorithm averaged in $2^{\circ} \times 2^{\circ}$ grid cells over 6 months from June to November 2015 . 


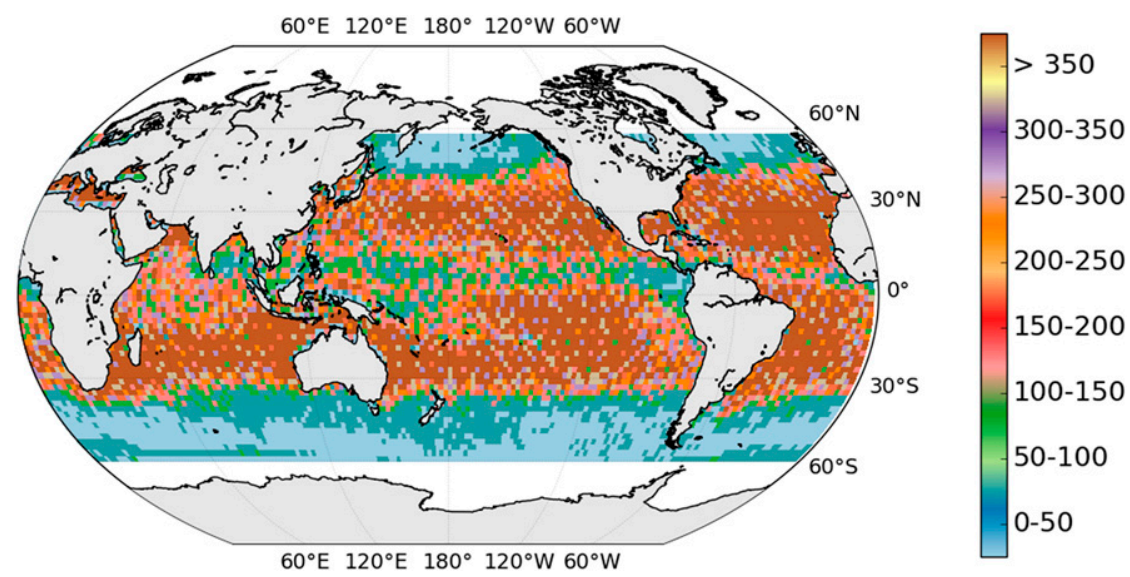

FIG. 12. Number of AMR clear-sky observations assimilated in the 1D-var scheme in each $2^{\circ} \times 2^{\circ}$ grid cell from June to November 2015 .

strongly differ from the "standard" ones, such as in upwelling areas characterized by complex vertical stratification of temperature and humidity profiles. To evaluate the contribution of the 1D-Var approach regarding the operational AMR WTC retrieval algorithm, a regional study is applied over the HA and WC upwelling areas, described in section 3. Figure 13 shows the distribution of retrieved humidity mean quadratic error with respect to background (named $\mathrm{MQE}_{1 \mathrm{DVAR}}$ ) anomaly in both upwelling areas (where surface-800-hPa temperature lapse rate is maximum). Here, the anomaly is defined as the ratio between $M_{1 D V A R}$ at a given grid cell and mean MQE $E_{1 D V A R}$, averaged over ocean from June to November 2015. The scale varies between 0 and 2 , with 0 meaning that $\mathrm{MQE}_{1 \mathrm{DVAR}}$ is negligible, 1 meaning that $\mathrm{MQE}_{1 \mathrm{DVAR}}$ is similar to mean $\mathrm{MQE}_{1 \mathrm{DVAR}}$, and 2 meaning that $M_{1 D V A R}$ is doubled regarding the mean MQE 1 DVAR. Figures $13 \mathrm{a}$ and $13 \mathrm{~b}$ show that the impact of the inversion of AMR measurements in the 1D-Var scheme on humidity in both upwelling areas is weak, with a mean MQE 1 DVAR anomaly around 0.7 and 0.8 in $\mathrm{HA}$ and $\mathrm{WC}$ areas respectively: $\mathrm{MQE}_{1 \mathrm{DVAR}}$ remains lower than global mean $M_{1 D V A R}$. Thus, retrieved humidity profiles remain close to background over both areas. This results in a higher retrieved WTC of only $0.2 \mathrm{~cm}$ regarding background and confirms that the systematic underestimated $\mathrm{WTC}_{1 \mathrm{DVAR}}$ with respect to $\mathrm{WTC}_{\mathrm{AMR}}$ of around $1 \mathrm{~cm}$, as shown in Figs. $13 \mathrm{c}$ and $13 \mathrm{~d}$, is mainly due to preexisting differences between background WTC and AMR estimated WTC.

\section{Discussion and conclusions}

The aim of this study is to explore the potential benefits and limits of a one-dimensional variational method to retrieve clear-sky WTC over global ocean.
We developed our assimilation method using a standalone 1D-Var tool available from the NWPSAF and we adapted it to allow the assimilation of passive microwave observations sensitive to the air humidity in the low-atmosphere levels and to surface properties. The 1D-Var gives as outputs profiles of temperature and humidity, which are then used to calculate WTC. To evaluate the 1D-Var tool, impact studies were performed using simulated measurements. Several configurations of pseudo-observations were tested: a classical low-frequency configuration similar to operational altimeter missions and a low-high-frequency configuration not yet used in the context of altimeter missions but very useful to prepare future altimeter missions, such as the Jason-CS mission expected in 2020.

The 1D-Var impact studies using "pseudomeasurements" showed that this approach allows the retrieval of WTC of improved quality with regard to the background. Root-mean-square errors of WTC are reduced with the assimilation of observations (with respect to the target WTC). When assimilating classical low-frequency observations, the mean impact on WTC are located in areas of high WTC in the low-latitude band, with a 3\%$4 \%$ error reduction between background and retrieved WTC. Improvements are also highlighted in upwelling areas, characterized by complex vertical stratification in the temperature and humidity profiles. Note that current statistical WTC estimation algorithms show large uncertainties in these regions. The impact of assimilating low- and high-frequency channels on retrieved WTC is larger on average than the impact of assimilating lowfrequency channels alone. The effect of their assimilation is extended to the low- and midlatitude bands, where WTC error is reduced by $5 \%$ between background and analyses. The 89- and 157-GHz-frequency channels showed the highest contribution to this error 


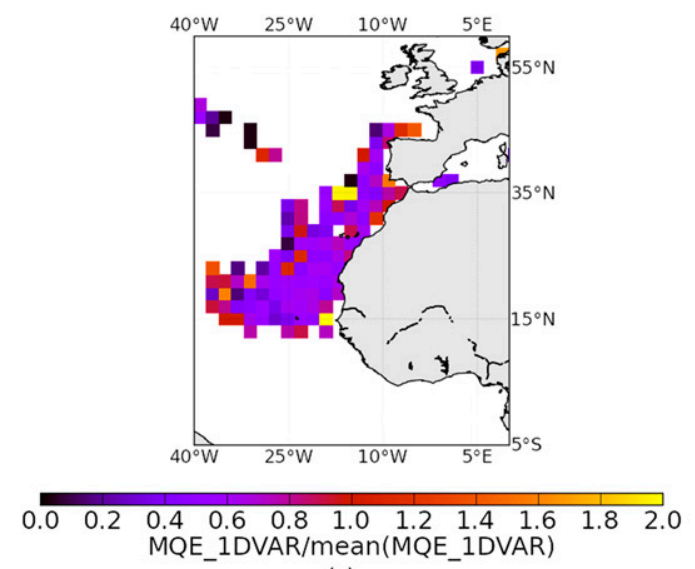

(a)

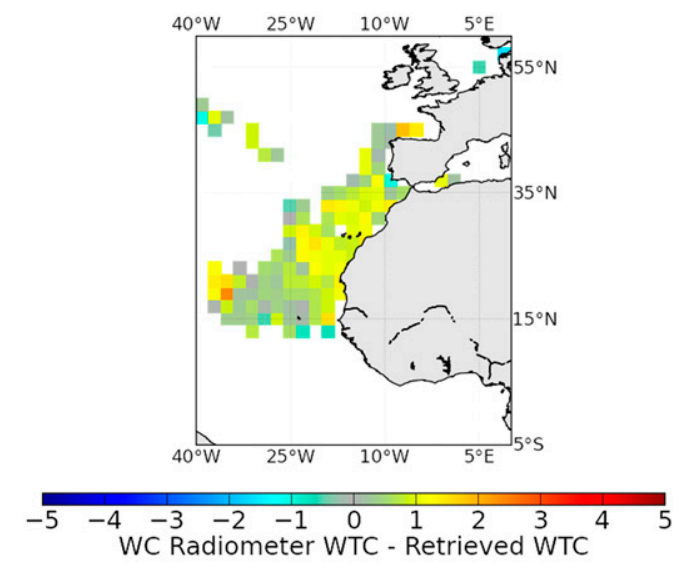

(c)

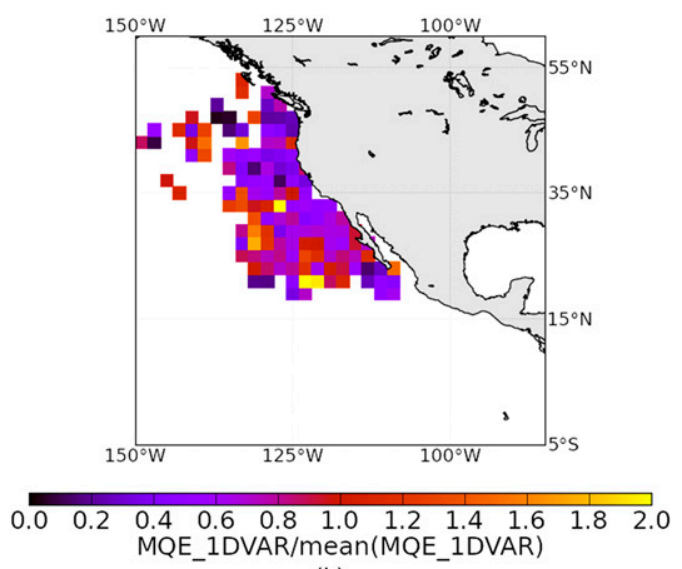

(b)

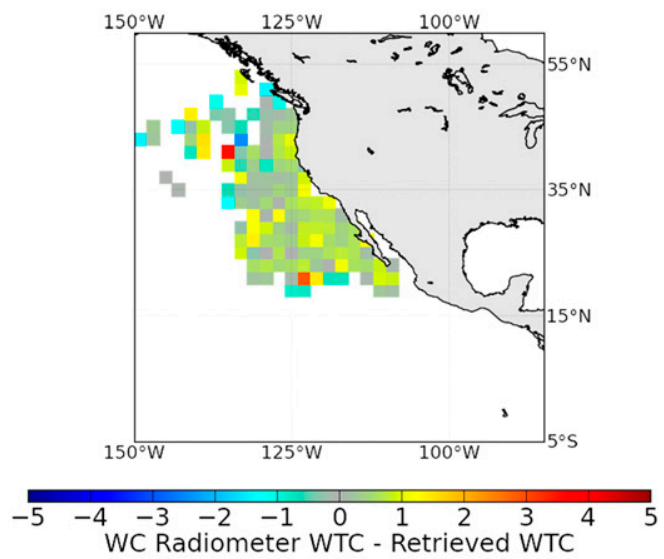

(d)

FIG. 13. (top) Retrieved-humidity mean quadratic error with respect to background anomaly over (a) HA and (b) WC upwelling areas, selected according to maximum values of the surface-800-hPa temperature lapse rate, and computed from June to November 2015 in $2^{\circ} \times 2^{\circ}$ grid cells. (bottom) AMR minus 1D-Var retrieved-WTC differences are computed over (c) HA and (d) WC upwelling areas.

reduction. This shows the benefit of the information content of such channels, sensitive to surface and low layers of the atmosphere. The contribution of the $190-\mathrm{GHz}$ channels seemed weaker, but these channels could be very useful for cloud screening.

We also evaluated the performances of the 1D-Var using real observations from the AMR radiometer on board Jason-2. The assimilation of these measurements (at low frequencies) results in an overall good agreement between retrieved and reference WTC (taken from the operational AMR WTC retrieval algorithm, available from the GDR products). Analyzed WTC were also compared with estimates from independent data derived from radio-occultation data. The comparison is in favor of the 1D-Var analyzed WTC. The assimilation of low- and high-frequency channels seems to be very promising but should be conducted with care. We looked at the potential use of the 1D-Var to retrieve WTC from real "low + high"-frequency measurements (results not shown in this paper).
Measurements were obtained from the AMSU-A and MHS onboard NOAA-18 and interpolated at nadir to simulate the altimeter-coupled radiometer measurements. The assimilation of these observations shows satisfactory results concerning the quality of analyzed WTC. The latter was found in good agreement with analyzed WTC when assimilating low-frequency channels. This means that we do not degrade the assimilation but that we still have to improve the assimilation of high-frequency channels to use the information content of these observations: among others, there is a need to better define observation errors, and to better screen for clouds.

The studies described above were conducted under clear-sky conditions. They underline the need to improve the assimilation of radiometer measurements from current altimeter missions under cloudy conditions. This requires accounting for some microphysical variables of clouds in the control variable of the 1D-Var, similarly to the study of Martinet et al. (2013). 


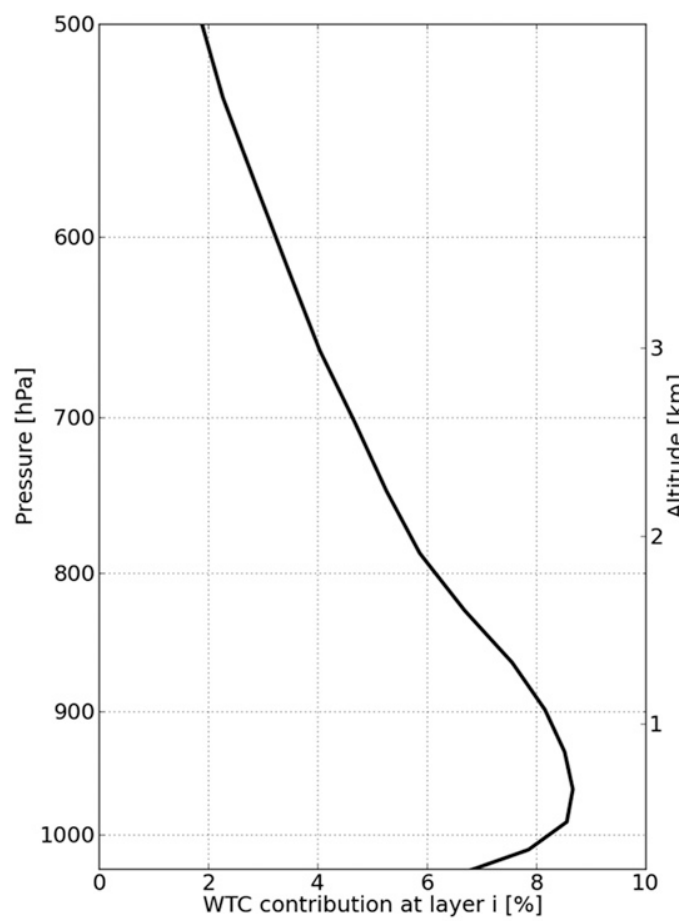

(a)

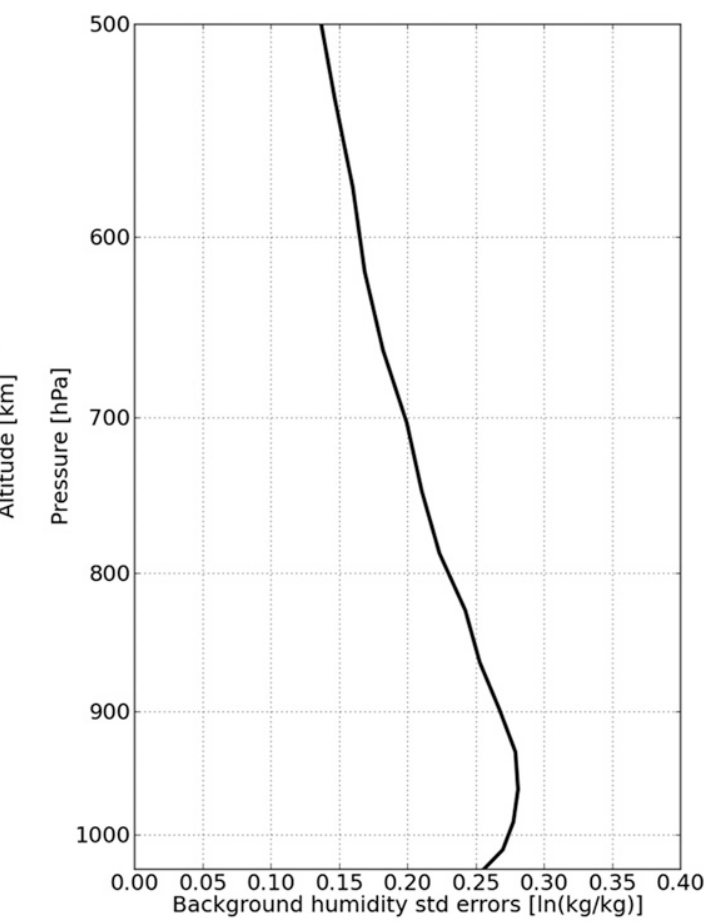

(b)

FIG. A1. (a) Contribution of each vertical layer to total integrated WTC (from surface to TOA), showing only from the surface to $500 \mathrm{hPa}$. (b) Background humidity standard deviation errors from surface to $500 \mathrm{hPa}$, derived from the NWPSAF background error covariance matrix and adapted to the contribution of each layer to total integrated WTC.

Acknowledgments. This work was supported by the CNES-TOSCA project. The authors are grateful to the ROM SAF for the use of their radio-occultation datasets.

\section{APPENDIX}

\section{Background Humidity Error Definition}

Background errors provided by the NWPSAF 1D-Var package over 54 fixed pressure levels are usually designed for temperature and humidity retrievals by assimilating sounding channels, peaking in the mid- and high troposphere. Thus, higher humidity errors are set in the higher-tropospheric layers and decrease when approaching the surface. In this study, the 1D-Var approach is used to estimate WTC from retrieved temperature and humidity profiles. Figure A1a shows the contribution of each pressure level to the integrated WTC from the surface to the top of the atmosphere. Almost $10 \%$ of the total WTC is formed in the lower troposphere, around the 950-1000-hPa interval. Thus, lower constraints are needed on retrieved humidity around these pressure levels, which implies higher background humidity errors. To better adapt the NWPSAF 1D-Var scheme to WTC estimation, humidity errors are weighted by the contribution of each pressure level to the integrated WTC. The new humidity standard deviation errors (diagonal coefficients of the background error covariance matrix) are illustrated in Fig. A1b.

\section{REFERENCES}

Ablain, M., A. Cazenave, G. Valladeau, and S. Guinehut, 2009: A new assessment of the error budget of global mean sea level rate estimated by satellite altimetry over 1993-2008. Ocean Sci., 5, 193-201, https://doi.org/10.5194/os-5-193-2009.

_- G. Larnicol, Y. Faugere, A. Cazenave, B. Meyssignac, N. Picot, and J. Benveniste, 2012: Error characterization of altimetry measurements at climate scales. 20 Years of Progress in Radar Altimetry Symp., Venice, Italy, ESA and CNES, http://www.aviso.altimetry.fr/fileadmin/documents/ OSTST/2012/oral/02_friday_28/04_errors_uncertainties_I/ 03_EU1_Ablain.pdf.

Bennartz, R., 1999: On the use of SSM/I measurements in coastal regions. J. Atmos. Oceanic Technol., 16, 417-431, https://doi.org/ 10.1175/1520-0426(1999)016<0417:OTUOSI > 2.0.CO;2.

— , and Coauthors, 2017: An intercalibrated dataset of total column water vapour and wet tropospheric correction based 
on MWR on board ERS-1, ERS-2, and Envisat. Atmos. Meas. Tech., 10, 1387, https://doi.org/10.5194/amt-10-1387-2017.

Bormann, N., A. Geer, and S. English, 2012: Evaluation of the microwave ocean surface emmisivity model FASTEM-5 in the IFS. European Centre for Medium-Range Weather Forecasts Tech. Memo. 667, 20 pp.

Boukabara, S.-A., and Coauthors, 2011: MiRS: An all-weather 1DVAR satellite data assimilation and retrieval system. IEEE Trans. Geosci. Remote Sens., 49, 3249-3272, https://doi.org/ 10.1109/TGRS.2011.2158438.

Brown, S., 2010: A novel near-land radiometer wet path-delay retrieval algorithm: Application to the Jason-2/OSTM advanced microwave radiometer. IEEE Trans. Geosci. Remote Sens., 48, 1986-1992, https://doi.org/10.1109/TGRS.2009.2037220.

_ C. Ruf, S. Keihm, and A. Kitiyakara, 2004: Jason microwave radiometer performance and on-orbit calibration. Mar. Geod., 27, 199-220, https://doi.org/10.1080/01490410490465643.

Deblonde, G., 2001: Variational retrievals using SSM/I and SSM/ $\mathrm{T}-2$ brightness temperatures in clear and cloudy situations. J. Atmos. Oceanic Technol., 18, 559-576, https://doi.org/ 10.1175/1520-0426(2001)018<0559:VRUSIA > 2.0.CO;2.

— crowave oceanic surface emissivity model. 11th Int. TOVS Study Conf., Budapest, Hungary, International TOVS Working Group, 67-78.

$\longrightarrow$, and $\longrightarrow$ 2003: One-dimensional variational retrievals from SSMIS-simulated observations. J. Appl. Meteor., 42, 1406-1420 https://doi.org/10.1175/1520-0450(2003)042<1406:OVRFSO >2.0. $\mathrm{CO} ; 2$.

Desportes, C., E. Obligis, and L. Eymard, 2007: On the wet tropospheric correction for altimetry in coastal regions. IEEE Trans. Geosci. Remote Sens., 45, 2139-2149, https://doi.org/ 10.1109/TGRS.2006.888967.

,$- \ldots$, and $\longrightarrow, 2010$ : One-dimensional variational retrieval of the wet tropospheric correction for altimetry in coastal regions. IEEE Trans. Geosci. Remote Sens., 48, 1001-1008, https://doi.org/10.1109/TGRS.2009.2031494.

ECMWF, 2012: IFS documentation-CY37R2: Operational implementation 18 May 2011. Part II: Data assimilation. ECMWF Rep., 174 pp.

Eymard, L., L. Tabary, E. Gérard, S. Boukabara, and A. Le Cornec, 1996: The microwave radiometer aboard ERS-1. II. Validation of the geophysical products. IEEE Trans. Geosci. Remote Sens., 34, 291-303, https://doi.org/10.1109/36.485108.

Eyre, J., 1991: A fast radiative transfer model for satellite sounding systems. ECMWF Tech. Memo. 176, 30 pp., https://doi.org/ 10.21957/xsg8d92y3.

Hewison, T. J., 2007: 1D-VAR retrieval of temperature and humidity profiles from a ground-based microwave radiometer. IEEE Trans. Geosci. Remote Sens., 45, 2163-2168, https://oi.org/ 10.1109/TGRS.2007.898091.

Keihm, S. J., M. A. Janssen, and C. S. Ruf, 1995: TOPEX/Poseidon microwave radiometer (TMR). III. Wet troposphere range correction algorithm and pre-launch error budget. IEEE Trans. Geosci. Remote Sens., 33, 147-161, https://doi.org/ 10.1109/36.368213.

Liu, Q., and F. Weng, 2005: One-dimensional variational retrieval algorithm of temperature, water vapor, and cloud water profiles from advanced Microwave Sounding Unit (AMSU). IEEE Trans. Geosci. Remote Sens., 43, 1087-1095, https://doi.org/ 10.1109/TGRS.2004.843211.

Martinet, P., N. Fourrié, V. Guidard, F. Rabier, T. Montmerle, and P. Brunel, 2013: Towards the use of microphysical variables for the assimilation of cloud-affected infrared radiances. Quart. J. Roy. Meteor. Soc., 139, 1402-1416, https://doi.org/ 10.1002/qj.2046.

Matricardi, M., F. Chevallier, G. Kelly, and J.-N. Thépaut, 2004: An improved general fast radiative transfer model for the assimilation of radiance observations. Quart. J. Roy. Meteor. Soc., 130, 153-173, https://doi.org/10.1256/ qj.02.181.

Obligis, E., L. Eymard, N. Tran, S. Labroue, and P. Femenias, 2006: First three years of the microwave radiometer aboard Envisat: In-flight calibration, processing, and validation of the geophysical products. J. Atmos. Oceanic Technol., 23, 802-814, https://doi.org/10.1175/JTECH1878.1.

— A. Rahmani, L. Eymard, S. Labroue, and E. Bronner, 2009: An improved retrieval algorithm for water vapor retrieval: Application to the Envisat microwave radiometer. IEEE Trans. Geosci. Remote Sens., 47, 3057-3064, https://doi.org/ 10.1109/TGRS.2009.2020433.

— , L. Eymard, M. Ablain, B. Picard, J. Legeais, Y. Faugère, and N. Picot, 2010: The wet tropospheric correction for altimetry missions: A mean sea level issue. Ocean Surface Topography Science Team Meeting, Lisbon, Spain, NASA, CNES, NOAA, and EUMETSAT, http://www.aviso.altimetry.fr/fileadmin/documents/ OSTST/2010/oral/19_Tuesday/OBLIGIS.pdf.

C. Desportes, L. Eymard, M. Fernandes, C. Lázaro, and A. Nunes, 2011: Tropospheric corrections for coastal altimetry. Coastal Altimetry, Springer, 147-176.

Picard, B., M.-L. Frery, E. Obligis, L. Eymard, N. Steunou, and N. Picot, 2015: SARAL/AltiKa wet tropospheric correction: In-flight calibration, retrieval strategies and performances. Mar. Geod., 38 (Suppl.), 277-296, https://doi.org/10.1080/ 01490419.2015 .1040903$.

Press, W. H., S. A. Teukolsky, W. T. Vetterling, and B. P. Flannery, 1988: Numerical Recipes. Cambridge University Press.

Ruf, C. S., and J. C. Giampaolo, 1998: Littoral antenna deconvolution for a microwave radiometer. Proc. Geoscience and Remote Sensing Symp., Seattle, WA, IEEE, 378-380, https:// doi.org/10.1109/IGARSS.1998.702911.

Saunders, R., M. Matricardi, and P. Brunel, 1999: A fast radiative transfer model for assimilation of satellite radiance observations-RTTOV-5. European Centre for MediumRange Weather Forecasts Tech. Memo. 282, 30 pp. 